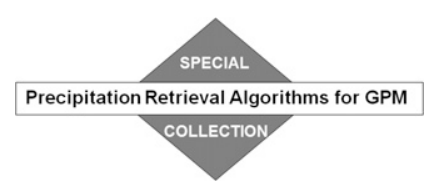

\title{
əInterpretation of the Precipitation Structure Contained in Polarimetric Radio Occultation Profiles Using Passive Microwave Satellite Observations
}

\author{
F. Joseph Turk, ${ }^{\mathrm{a}}$ Ramon Padullés, ${ }^{\mathrm{b}, \mathrm{c}}$ Estel CARdellach,${ }^{\mathrm{b}, \mathrm{c}}$ Chi O. Ao, ${ }^{\mathrm{a}}$ KuO-Nung Wang, ${ }^{\mathrm{a}}$ \\ David D. Morabito, ${ }^{a}$ Manuel de la Torre Juarez, ${ }^{a}$ Mayra Oyola,${ }^{a}$ Svetla Hristova-Veleva, ${ }^{a}$ And \\ J. DAVID NEELIN ${ }^{\mathrm{d}}$ \\ a Jet Propulsion Laboratory, California Institute of Technology, Pasadena, California \\ ${ }^{\mathrm{b}}$ Instituto de Ciencias del Espacio (ICE-CSIC), Barcelona, Spain \\ ${ }^{\mathrm{c}}$ Institute of Space Studies of Catalonia (IEEC), Barcelona, Spain \\ ${ }^{\mathrm{d}}$ Department of Atmospheric and Oceanic Sciences, University of California, Los Angeles, \\ Los Angeles, California
}

(Manuscript received 14 April 2021, in final form 9 July 2021)

\begin{abstract}
Observationally, a major source of uncertainty in evaluation of climate models arises from the difficulty in obtaining globally distributed, fine-scale profiles of temperature, pressure, and water vapor that probe through convective precipitating clouds, from the boundary layer to the upper levels of the free troposphere. In this manuscript, a 2-yr analysis of data from the Radio Occultations through Heavy Precipitation (ROHP) polarimetric radio occultation (RO) demonstration mission onboard the Spanish Paz spacecraft is presented. ROHP measures the difference in the differential propagation phase delay $(\Delta \phi)$ between two orthogonal polarization receive states that is induced from the presence of nonspherically shaped hydrometeors along the Global Navigation Satellite System (GNSS) propagation path, complementing the standard RO thermodynamic profile. Since $\Delta \phi$ is a net path-accumulated depolarization and does not resolve the precipitation structure along the propagation path, orbital coincidences between ROHP and the Global Precipitation Measurement (GPM) constellation passive microwave (MW) radiometers are identified to provides threedimensional precipitation context to the RO thermodynamic profile. Passive MW-derived precipitation profiles are used to simulate the $\Delta \phi$ along the ROHP propagation paths. Comparison between the simulated and observed $\Delta \phi$ are indicative of the ability of ROHP to detect threshold levels of ray-path-averaged condensed water content, as well as to suggest possible inferences on the average ice-phase hydrometeor nonsphericity. The use of the polarimetric RO vertical structure is demonstrated as a means to condition the lower-tropospheric humidity by the topmost height of the associated convective cloud structure.
\end{abstract}

SIGNIFICANCE STATEMENT: The Radio Occultations and Heavy Precipitation (ROHP) experiment, orbiting onboard the Spanish Paz satellite since May 2018, has demonstrated the polarimetric RO capability to simultaneously detect the presence of precipitation alongside standard RO thermodynamic processing yielding temperature, pressure, and moisture profiles. In this investigation, ROHP data are simulated by using precipitation profiles estimated from near-simultaneous passive MW satellite data. Comparisons between simulated and actual ROHP data reveal the ability of the polarimetric RO signal to detect threshold levels of ray-path-averaged condensed water content, to infer the average ice-phase hydrometeor nonsphericity, and to serve as a proxy for conditioning the lower-tropospheric humidity by the topmost height of the associated convective cloud structure.

KEYWORDS: Atmosphere; Precipitation; Humidity; Global positioning systems (GPS); Microwave observations; Satellite observations; Model evaluation/performance

\section{Introduction}

The study of tropical convection and the resulting precipitation is motivated by difficulties in their representation in global circulation models (Sherwood et al. 2014). A conventional

\footnotetext{
¿ Denotes content that is immediately available upon publication as open access.
}

Corresponding author: F. J. Turk, jturk@jpl.caltech.edu diagnostic for climate models emphasizes comparisons against observed precipitation climatology (Tapiador et al. 2019). Using data from the Tropical Rainfall Measuring Mission (TRMM), Bretherton et al. (2004) established a relationship between total column integrated precipitable water vapor (TPW) and precipitation. Process-based diagnostics have been developed such as convective transition statistics, which describe the relation between TPW and precipitation. More recent studies have refined this relationship via relative contributions to conditional instability from different free-tropospheric layers versus the boundary layer, in terms of dynamic entrainment 
profiles (Ahmed and Neelin 2018; Schiro and Neelin 2019; Schiro et al. 2020). These diagnostics provide a set of constraints on the convective parameterizations used in climate models (Kuo et al. 2018). To assess the global convective transition statistics across models, satellite-derived precipitation data are readily available from TRMM and the current Global Precipitation Measurement (GPM) satellite data products. A major source of uncertainty remains from the difficulty in obtaining a sufficient quantity of globally distributed, fine-scale (100-200-m resolution) vertical profiles of temperature $(T)$, pressure $(p)$, and moisture $(q)$, through the boundary layer to the upper levels of the free troposphere, that probe internal to convective precipitating clouds (Geerts et al. 2018). The objective of the work presented in this manuscript is to investigate this observational gap with the use of Global Navigation Satellite System (GNSS) radio occultation (RO) observations, specifically those obtained from the Radio Occultations through Heavy Precipitation (ROHP) demonstration onboard the Spanish Paz spacecraft, deployed in 2018 (Cardellach et al. 2019; Padullés et al. 2020).

While the main use of GNSS-RO data to date is within the numerical weather prediction (NWP) data assimilation community (Ruston and Healy 2021), the GNSS-RO measurement has unique advantages for use with convective transition relationships. The measurement of the thermodynamic parameters is not based on attenuation or backscatter by clouds and precipitation at the GNSS carrier frequency (L band, near $1.4 \mathrm{GHz}$ ) but by propagation delay time, making RO practical for probing through extreme precipitation weather systems and in the nearby environment with similar accuracy. Established RO processing techniques provide the bending angle profile from which $(T, p, q)$ retrievals are made at the requisite vertical resolution ( $\sim 100 \mathrm{~m}$ to $1 \mathrm{~km}$, depending on height) necessary to separate water vapor within different vertical layers (Kursinski et al. 1997). Currently, the presence of clouds is determined indirectly through analysis of refractivity gradients or temperature lapse rates (Mascio et al. 2021; Lasota et al. 2018). ROHP represents a space-based demonstration for detecting the presence of precipitating clouds by using the polarimetric RO (PRO) measurement concept (Cardellach et al. 2014). When the GNSS signal propagates through a region of nonspherical hydrometeors such as oblate-shaped rain precipitation, a propagation differential (horizontal minus vertical, or $\mathrm{H}-\mathrm{V}$ ) phase delay is induced, denoted as $\Delta \phi=\phi_{\mathrm{H}}-$ $\phi_{\mathrm{V}}$ and measurable with a dual orthogonal $(\mathrm{H} / \mathrm{V}) \mathrm{RO}$ receiver capability (Fig. 1). The measurement is somewhat analogous to the cumulative propagation differential phase shift $\left(\phi_{\mathrm{dp}}\right)$ measured by the operational National Atmospheric and Oceanic Administration (NOAA) NEXRAD radar network, but only the forward propagation aspects (i.e., 1way $\phi_{\mathrm{dp}}$ before backscatter) (Bringi and Chandrasekar 2001). The value of $\Delta \phi$ is derived separately from the RO processing of the excess phase delay (incurred by propagation through water vapor gradients) used for processing of the standard $(T, p, q)$ retrieval. The ROHP demonstration mission has successfully demonstrated the PRO concept, with (to date) over 3 years of data (Cardellach et al. 2019;

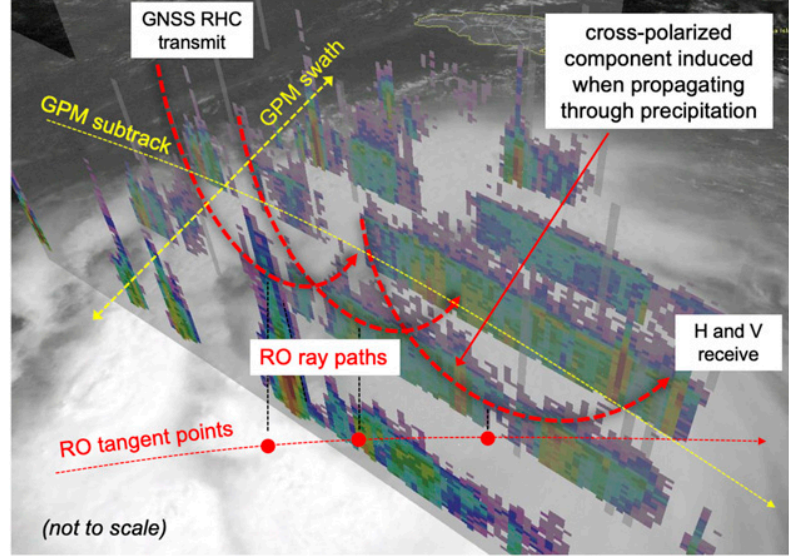

FIG. 1. Pictorial depiction of a polarimetric radio occultation (PRO). In this example, the occultation sets through a heavy precipitation event observed near-simultaneously by the scanning GPM Microwave Imager (GMI), whose TB are inverted to provide an estimate of the vertical precipitation structure (colored vertical profiles). As the RHC-polarized GNSS signal propagates through the precipitation media (the three red lines), a cross-polarized (LHC) component is induced owing to hydrometeor asphericity. The ROHP receiver onboard the Paz satellite measures the amplitude and phase of the co- and cross components in a linear $(\mathrm{H}$ and $\mathrm{V})$ receive basis. For clarity, only five along-track profiles of the vertical precipitation structure are shown.

Padullés et al. 2020), providing about 200 PRO per day. Currently, only the (nonpolarimetric) bending angle data from ROHP are assimilated into operational NWP models. To make additional use of the polarimetric RO data for precipitation science investigations and weather modeling, a broader understanding of the $\Delta \phi$ profile as function of the moisture and precipitation conditions is needed (Padullés et al. 2021; Wang et al. 2021).

In this investigation, near-coincident observations between ROHP and the passive microwave (MW) radiometric satellite observations that make up the current GPM satellite constellation (Kidd et al. 2018) are used to simulate the $\Delta \phi$ profile by the associated three-dimensional precipitation conditions. Depending upon the sensor, these radiometers scan a wide swath and whose equivalent blackbody brightness temperature (TB) imagery can provide three-dimensional context to the precipitation structure that is not discernable from the ROHP $\Delta \phi$ observations alone. There is a large body of published work on the complementary use of RO and passive MW sounder data for radiance-level intercalibration for the Advanced Technology Microwave Sounder (ATMS) (Iacovazzi et al. 2020) and Microwave Humidity Sounder (MHS) (Isoz et al. 2015). This investigation utilizes these passive MW data in an opposite context, whereby the passive MW observations are inverted into precipitation water content profiles along the ROHP propagation ray paths. These joint data facilitate this investigation to examine uncertainties in the interpretation of $\Delta \phi$. 


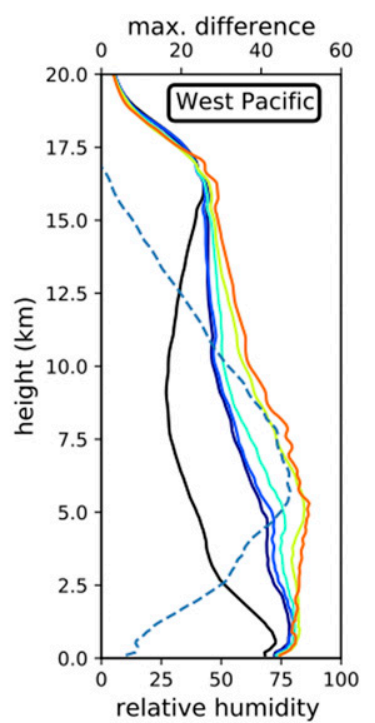

(\%)

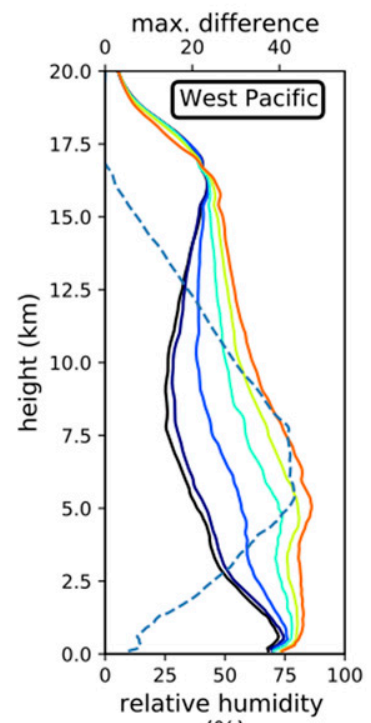

(\%)

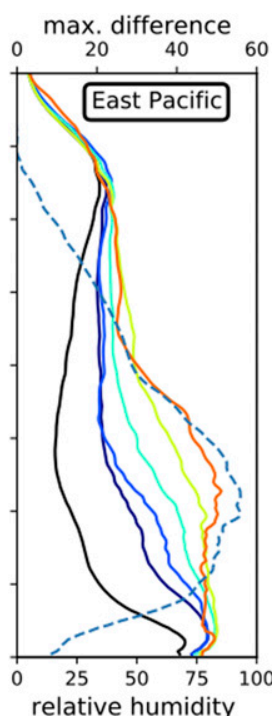

$(\%)$

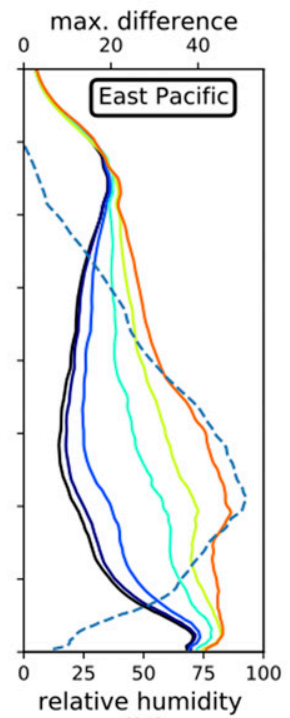

(\%)

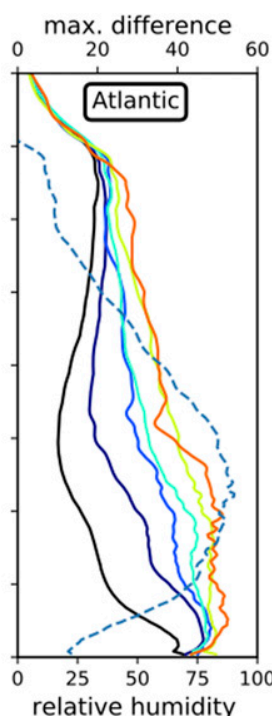

$(\%)$

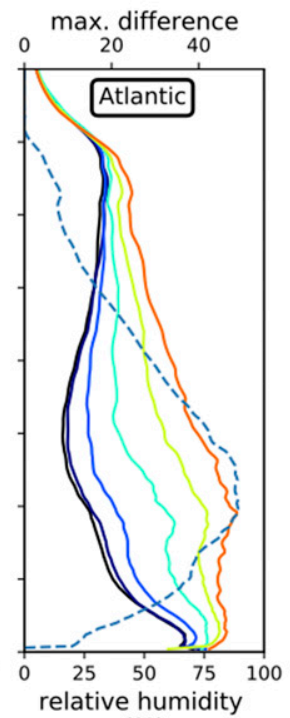

(\%)

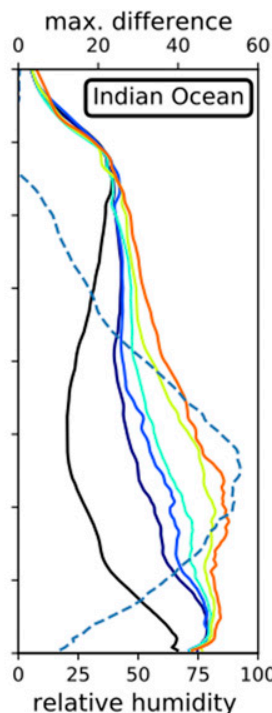

(\%)

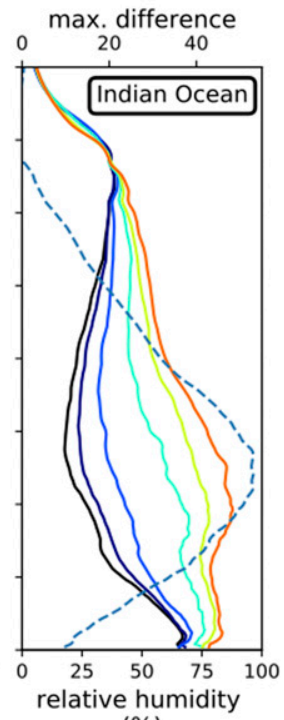

(\%)

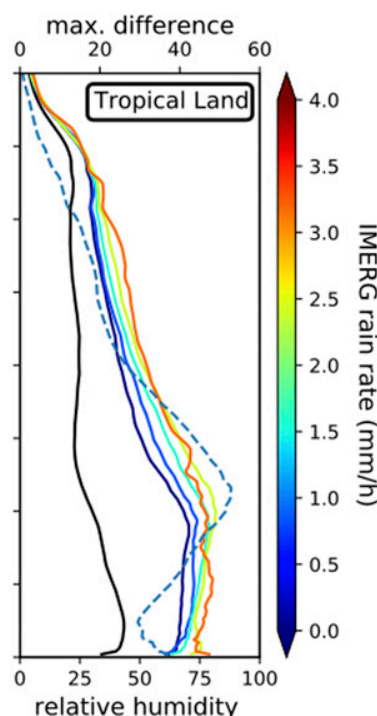

(\%)

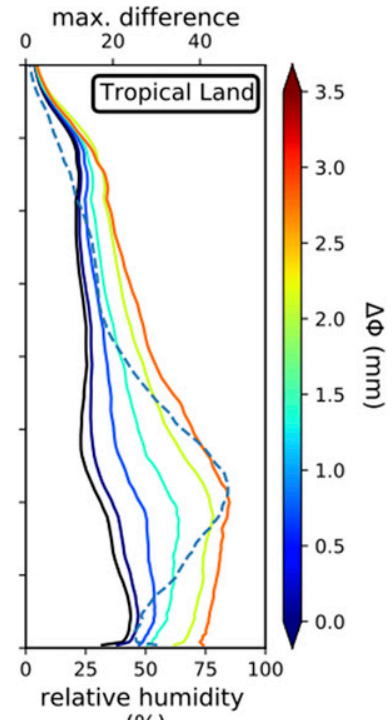

(\%)

FIG. 2. (top) Vertical humidity from all ROHP data between $\pm 30^{\circ}$ latitude during $2018-20$, separated by four oceanic basins (west Pacific, east Pacific, Atlantic, and Indian Oceans) and all land areas within this latitude band. Each solid line curve is an average for when these data are further conditioned by the average IMERG rain rate surrounding each profile (e.g., the black and red lines indicate an average of all profiles when $R=0$ and $R>4 \mathrm{~mm} \mathrm{~h}^{-1}$, respectively). The dashed line represents the maximum-minus-minimum difference at each vertical level, revealing a sensitivity to moisture in the midtroposphere. (bottom) As in the top row, but the data are conditioned by the average $\Delta \phi$ within the profile.

In section 3, this concept is demonstrated from analysis of two years of ROHP data, matched to near time-coincident passive MW radiometer data from the GPM Microwave Imager (GMI) and the Special Sensor Microwave Imager/Sounder (SSMIS). To evaluate ROHP's capability to detect the presence of precipitation at various levels within the RO, a raytracing model is projected through the precipitation structure estimated by the emissivity principal components (EPC) passive MW precipitation profiling retrieval (Turk et al. 2018; Utsumi et al. 2020). To examine overall sensitivity to hydrometeor shape, simulations of $\Delta \phi$ are compared to the observed
$\Delta \phi$ in different vertical levels. Using basic assumptions for ice hydrometeor shape, these comparisons reveal possible inferences to the mean hydrometeor asphericity along each PRO ray path. Section 4 demonstrates how the $\Delta \phi$ vertical structure is a useful proxy for discrimination of lowertropospheric moisture profiles under convective conditions, proposed in the Turk et al. (2019) RO small satellite constellation strategy. This manuscript concludes by describing how these simulations form the basis for a simplified PRO forward operator that could be further developed alongside existing RO bending angle operators, adapting hydrometeor 
TABLE 1. Passive microwave (MW) satellites of opportunity used for determination of swath coverage from RO events. GMI, AMSR-2, and SSMIS are conically scanning passive MW imagers; the remainder are across-track scanning passive MW sounders. DMSP $=$ Defense Meteorological Satellite Program, NPP = National Polar Orbiting Partnership, JPSS = Joint Polar Satellite System, GCOM-W = Global Change Observing Mission for Water, GPM = Global Precipitation Measurement, AMSR-E = Advanced Microwave Scanning Radiometer for EOS, SSMIS = Special Sensor Microwave Imager/Sounder, MHS = Microwave Humidity Sounder, GMI $=$ GPM Microwave Imager, ATMS = Advanced Technology Microwave Sounder, SAPHIR = Sounder for Probing Vertical Profiles of Humidity, LTAN $=$ local time of ascending node.

\begin{tabular}{|c|c|c|c|c|c|c|c|}
\hline Satellite & Sensor & $\begin{array}{l}\text { Channels } \\
<\sim 90 \mathrm{GHz}\end{array}$ & $\begin{array}{l}\text { High-frequency } \\
\text { channels }(\mathrm{GHz})\end{array}$ & $\begin{array}{l}\text { Resolution } \\
(\mathrm{km})\end{array}$ & $\begin{array}{l}\text { Swath } \\
(\mathrm{km})\end{array}$ & Pixels/scan & LTAN (early 2021) \\
\hline GPM & GMI & $\begin{array}{c}10.65(\mathrm{~V} / \mathrm{H}) \\
18.65(\mathrm{~V} / \mathrm{H}) \\
23.8(\mathrm{~V}) \\
36.5(\mathrm{~V} / \mathrm{H})\end{array}$ & $\begin{array}{c}89.0(\mathrm{~V} / \mathrm{H}) \\
166.0(\mathrm{~V} / \mathrm{H}) \\
183.3 \pm 3(\mathrm{~V}) \\
183.3 \pm 7(\mathrm{~V})\end{array}$ & $\sim 7$ & 880 & 221 & 65-day repeat \\
\hline$G C O M-W$ & AMSR-2 & $\begin{array}{l}10.65(\mathrm{~V} / \mathrm{H}) \\
18.65(\mathrm{~V} / \mathrm{H}) \\
23.8(\mathrm{~V} / \mathrm{H}) \\
36.5(\mathrm{~V} / \mathrm{H})\end{array}$ & $89.0(\mathrm{~V} / \mathrm{H})$ & $\sim 7$ & 1450 & $\begin{array}{l}243 \\
486\end{array}$ & 1330 \\
\hline $\begin{array}{l}\text { DMSP } \\
F-16 \\
F-17 \\
F-18\end{array}$ & SSMIS & $\begin{array}{l}19.35(\mathrm{~V} / \mathrm{H}) \\
22.235(\mathrm{~V}) \\
37.1(\mathrm{~V} / \mathrm{H})\end{array}$ & $\begin{array}{c}91.7(\mathrm{~V} / \mathrm{H}) \\
150(\mathrm{H}) \\
183.3 \pm 1 \\
183.3 \pm 3 \\
183.3 \pm 6.6(\mathrm{H})\end{array}$ & 14 & 1700 & $\begin{array}{c}90 \\
180\end{array}$ & $\begin{array}{l}1600 \\
1840 \\
1720\end{array}$ \\
\hline $\begin{array}{l}N P P \\
N O A A-20\end{array}$ & ATMS & $\begin{array}{l}23.8(\mathrm{~V}) \\
31.4(\mathrm{~V})\end{array}$ & $\begin{array}{c}88.2(\mathrm{~V}) \\
165.5(\mathrm{~V}) \\
183.3 \pm 1 \\
183.3 \pm 1.8 \\
183.3 \pm 3 \\
183.3 \pm 4.5 \\
183.3 \pm 7(\mathrm{H})\end{array}$ & $14-45$ & 2500 & 96 & $\begin{array}{l}1330 \\
1330\end{array}$ \\
\hline $\begin{array}{l}\text { NOAA-19 } \\
\text { MetOp-A } \\
\text { MetOp-B }\end{array}$ & MHS & & $\begin{array}{c}89.0(\mathrm{~V}) \\
157.0(\mathrm{~V}) \\
183.3 \pm 1 \\
183.3 \pm 3(\mathrm{H}) \\
191.3(\mathrm{~V})\end{array}$ & $17-40$ & 2500 & 90 & $\begin{array}{l}1700 \\
2100 \\
2130\end{array}$ \\
\hline Megha-Tropiques & SAPHIR & & $\begin{array}{r}183.3 \pm 0.2 \\
183.3 \pm 1.1 \\
183.3 \pm 2.8 \\
183.3 \pm 4.2 \\
183.3 \pm 6.8 \\
183.3 \pm 11(\mathrm{H})\end{array}$ & $10-22$ & 1700 & 182 & $\begin{array}{c}\text { 51-day repeat (ground } \\
\text { track repeat every } \\
7 \text { days) }\end{array}$ \\
\hline
\end{tabular}

electromagnetic scattering models previously developed for assimilation of precipitation-affected passive MW radiances.

\section{Quantifying joint passive MW coverage for ROHP}

The rationale for use of PRO data for convective transition statistics is demonstrated by an analysis from the first two years of ROHP data (beginning May 2018), conditioned by two different metrics for precipitation conditions as shown in Fig. 2. In the top row of Fig. 2, the relative humidity profile from all ROHP data covering $\pm 30^{\circ}$ latitude is shown, separated by five regions (west Pacific, east Pacific, Atlantic, and Indian Oceans, and all land areas) within this latitude band. Each solid line curve represents the average profile when these data are conditioned by the average GPM Integrated Merged (IMERG) rain rate surrounding each profile (e.g., the black and red lines indicate an average of all profiles when $R=0$ and $R>4 \mathrm{~mm} \mathrm{~h}^{-1}$, respectively). The dashed line represents the maximum-minus-minimum difference at each vertical level. While there are regional differences, this analysis indicates that heavy precipitation has the largest sensitivity to moisture residing not near the surface where the majority of water vapor resides, rather in the midtroposphere. The bottom row of Fig. 2 shows these same data, the only difference being that the separation is done by the average $\Delta \phi$ within the profile. A similar response is shown, indicating that the presence of $\Delta \phi$ above a threshold can serve as a proxy for separation of RO data by IMERG precipitation conditions. $\Delta \phi$ represents a direct matched measurement, sampling the same air mass path used to estimate $T, p$, and $q$, regardless of precipitation intensity. However, $\Delta \phi$ is a ray-path-accumulated measurement; the same 


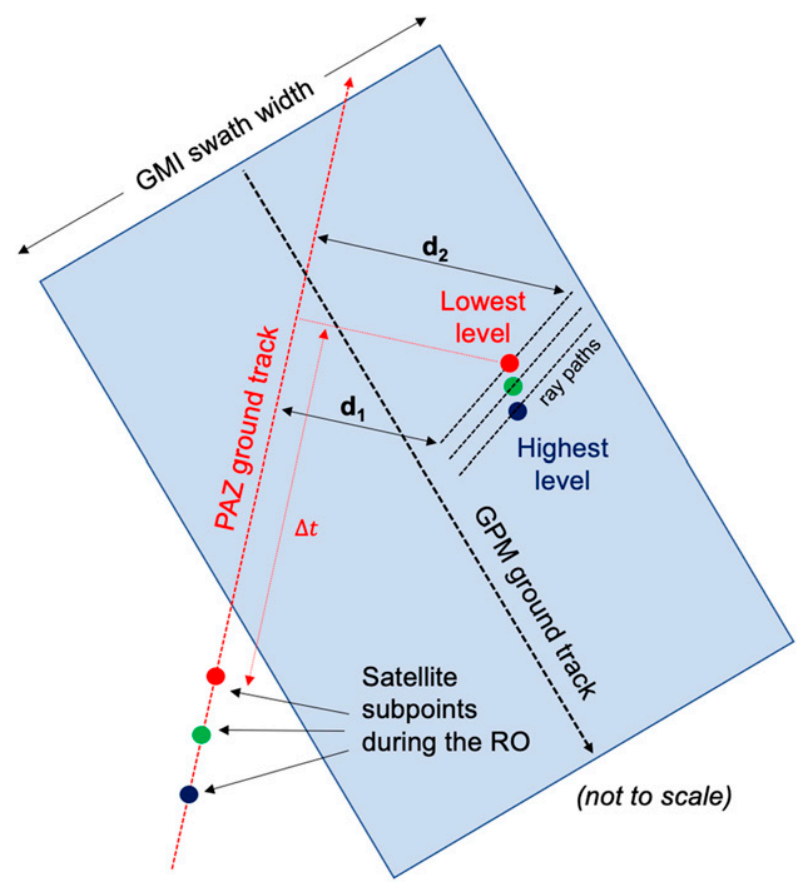

FIG. 3. Pictorial depiction (not to scale) of coincidence between a $P a z$-ROHP radio occultation (RO) and a GPM descending overpass. A $400-\mathrm{km}$ ray path is assumed along the azimuth of the RO ray path, whose lowest-level tangent point is shown with the red dot. In this example, the entire ray path falls within the swath of the GMI radiometer. The distance $d_{2}$ represents the maximum distance between the Paz subtrack and the ray path of the lowest level ray in the RO. The time offset between the time of the lowest level $\mathrm{RO}$ and its closest proximity to the Paz subtrack is denoted by $\Delta t$.

value could result from different precipitation conditions along each ray path.

To gather two-dimensional context on the clouds at the time of a RO, one option is to consult fast-refresh (15-min or less) geostationary satellite imagery. The current network of geostationary satellites has common channels in the thermal infrared (IR) longwave (near $11-\mu \mathrm{m}$ wavelength) for tracking the evolution of optically thick cloud tops (Fiolleau and Roca 2013), but provide no direct detail on the precipitation structure underneath the cloud top. The sensitivity of the W-band (94 GHz) nadir-only CloudSat Profiling Radar (CPR) and the GPM Dual-Frequency Precipitation Radar (DPR) to cloud vertical structure is preferred, but the DPR radars are limited in swath coverage ( 245 and $125 \mathrm{~km}$ in the case of the DPR Ku- and Ka-band radars, or 14 and $35 \mathrm{GHz}$ ) needed to encompass lengthy lower-tropospheric RO propagation paths. Wide-swath (e.g., 1000-km or more) passive MW observations have the potential to augment the interpretation of RO with knowledge of the precipitation context. This complementary coverage is quantified by the percentage of events that would be jointly covered by overlaps with passive MW imagers and sounders onboard the LEO satellites making up the GPM constellation, shown in Table 1. Coverage was done by checking the ROHP RO with each
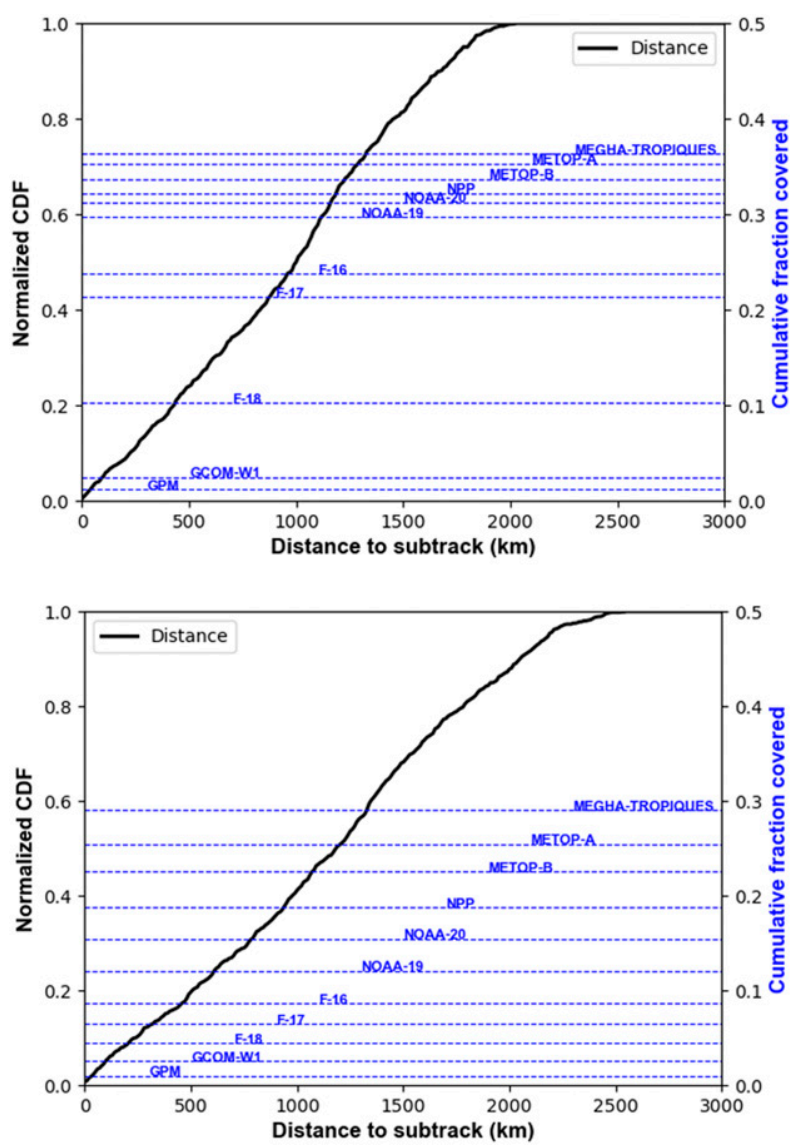

FIG. 4. (top) Summary of the fraction of ROHP RO that are captured by passive MW swath coverage within \pm 15 min of the RO time. The cumulative coverage (right vertical axis) considers passive MW swath coverage from sensors in Table 1, and shown by the series of horizontal blue lines (lowest line $=$ GMI only, next line above $=$ GMI + AMSR2, ..., highest line $=$ all 11 sensors in Table 1). The black line shows the normalized cumulative distribution function (CDF) of the distance between each RO and the $P a z$ satellite subtrack (Fig. 3). (bottom) As in the top panel, but for the six-satellite COSMIC-2 constellation.

satellite in Table 1 in sequence. $A \pm 15$-min maximum allowable time offset between the RO and the satellite overpass time is considered.

To demonstrate, Fig. 3 shows a pictorial depiction of a coincidence between ROHP and a GPM descending overpass. A $400-\mathrm{km}$ ray path is assumed along the azimuth of the RO ray path (this distance assumption is quantified in section 3), whose lowest level tangent point (TP) is shown with the red point. The time offset between the time of the lowest level RO and its closest proximity to the Paz subtrack (labeled as $\Delta t$ ) is $\sim 5 \mathrm{~min}$ or less. In this example, the entire ray path falls within the swath of the GMI radiometer. If it had not, a similar coverage check would have been carried out for AMSR-2, etc., stopping when coverage was located. The horizontal blue lines in Fig. 4a summarize the results for coincidences with ROHP RO data. For example, if only GMI is considered, less than $1 \%$ of the RO are covered. If GMI, AMSR-2, and the DMSP F-18, F-17, and 
F-16 SSMIS are considered, these five radiometers collectively capture about $24 \%$ of the events. If all 11 radiometers in Table 1 are considered, it can be seen that almost $37 \%$ of the RO events will be captured with passive MW coverage. For comparison, Fig. 4b shows this same analysis carried out with RO the six-satellite Constellation Observing System for Meteorology, Ionosphere and Climate (COSMIC-2) (Ho et al. 2020). While COSMIC-2 overall sampling numbers are substantially higher than ROHP, percentage-wise the coincidence opportunities are slightly higher for ROHP. Note that by virtue of the 1800 local time of ascending node (LTAN) sunsynchronous $\mathrm{Paz}$ polar orbit, most of the coincidences occur with the similar-time DMSP satellites, and very few with the afternoon crossing NPP and NOAA-20 satellites. By contrast, the coincidences are more equally distributed across sensors for the COSMIC-2 $24^{\circ}$-inclined orbit plane.

For comparison, the solid black line in Fig. 4a shows the normalized histogram of the longest distance between the $\mathrm{Paz}$ subtrack and the ray path (shown as $d_{2}$ in Fig. 3). This is a proxy for the half-swath width that a fictitious across-track scanning passive MW radiometer onboard the Paz spacecraft that would be needed to capture the same fraction of RO events (the RO can lie on either side of the $P a z$ subtrack). It can be seen that a passive MW radiometer onboard $\mathrm{Paz}$ with a swath width of about $2500 \mathrm{~km}$ (similar to ATMS) would yield the same percent coverage as all the satellites of opportunity in Table 1. Note that this assessment does not take into consideration the desired channel sets on the radiometers needed to estimate the corresponding precipitation profile, which is beyond the scope of this investigation. Generally speaking, the conically scanning radiometers (first three rows of Table 1) are preferred owing to their near-constant Earth incidence angle and resolution across the scan (You et al. 2020). Repeating this exercise only for the conical radiometers, the total coverage is $25 \%$.

For the remainder of this manuscript, 1995 cases were collected for \pm 15 -min coincidences between ROHP and GPM, and 5934 cases between ROHP and DMSP F-18, covering the period from 26 July 2018 through 22 August 2020 (7929 cases total). The ROHP wet profile retrieval datasets were obtained from the Institute of Space Sciences (IEEC-CSIC), each providing the temperature, pressure, partial pressure, and refractivity profile at $0.1-\mathrm{km}$ vertical resolution as processed by the COSMIC Data Analysis and Archive Center (CDAAC). A quality flag is consulted which indicates the lowest level below which the retrieval failed to converge owing to low signal-to-noise ratio. If this level is below $3-\mathrm{km}$ height, the data are retained for further analysis.

\section{Interpretation of $\Delta \phi$ using passive MW observations}

To provide insight into the precipitation structure along the ray paths, the EPC passive MW precipitation profiling retrieval (Turk et al. 2018) is used. Similar passive MW profiling retrievals are routinely produced by the GPM Goddard Profiling (GPROF) (Kummerow et al. 2015) algorithm for GPM constellation radiometer processing, and by the Microwave Integrated Retrieval System (MiRS) (Liu et al. 2020) for operational purposes at NOAA. Utsumi et al.
(2020) evaluated the vertical precipitation profiles estimated by the EPC and GPROF algorithms, relative to the GPM DPR combined algorithm (CORRA) profile (Grecu et al. 2016). Similar to GPROF, the EPC passive MW retrieval is a Bayesian-based inversion, connecting the multichannel TB from each sensor listed in Table 1, to the precipitation profile estimated by the limited swath GPM Ku- and Ka-band radars via sensor-specific a priori data (appendix A of Turk et al. 2018). The resulting EPC products contain the precipitation profile structure for each radiometer pixel across the scan (Table 1), posted at the same $0.25-\mathrm{km}$ height levels used in the a priori water content profile products from the CORRA profile products.

\section{a. Estimation of condensed water path along the $R O$ ray path}

For each ROHP profile, the observed $\Delta \phi$ profile was compared to the simulated $\Delta \phi$ profile. The simulation procedure follows the flow diagram in Fig. 5. The EPC retrieval is run for enough radiometer scan lines to cover the latitude-longitude extent of the RO ray paths from $20 \mathrm{~km}$ to the surface. In this work, a 3D ray-tracing program developed at JPL (Mannucci et al. 2011) is used to propagate the GNSS signal from the GNSS transmitter to the LEO receiver. The inputs to the raytracing program include the transmitter and receiver trajectories as well as specification of the atmosphere (either in the form of 1D refractivity profile or 3D refractivity grids). Each occultation consists of a time series of transmitter and receiver positions. At each received time, a ray is launched from the transmitter position, traced through the atmosphere, and arrived in the vicinity of the receiver position. The launch angles are then adjusted so that the ray will converge to the desired receiver position within some specified tolerance. In this way, the correct ray path at each received time is obtained. Given the ray-path locations, any path-integrated physical parameter such as the excess phase delay at horizontal or vertical polarization can be easily derived. This ray-tracing model propagates (at each 100 -m vertical level) the RO ray through the 3D precipitation structure produced by the EPC, whenever the ray is below $20-\mathrm{km}$ height.

To illustrate, the geometry of a ROHP setting RO near $\left(35^{\circ} \mathrm{S}, 11^{\circ} \mathrm{W}\right)$ at 0544 UTC 15 April 2019 is depicted in Fig. 6a. Only the portion of the rays that fall below $20-\mathrm{km}$ altitude is shown. Each ray is spaced by $0.1 \mathrm{~km}$ in the vertical, corresponding to the spacing used in the ROHP wet profile retrieval product. For perspective, any ray that falls below 4-km height is plotted in red, and the portion of the ray below $4 \mathrm{~km}$ is further shaded in magenta. Figure $6 \mathrm{~b}$ shows the projection of the rays upon the surface. For the lowest ray, the projected distance is $\sim 400 \mathrm{~km}$. During the time that the rays have fallen below $4-\mathrm{km}$ height, the tangent point (TP; the location of the lowest level in each ray, shown in blue) drifts by about $20 \mathrm{~km}$.

Figure 7 show these same RO ray paths superimposed upon SSMIS imagery from the DMSP $F$ - 18 overpass near 0555 UTC, in the southern Atlantic Ocean. In Fig. 7a, the precipitation structure is noted in the radiometrically warmer (relative to the surrounding environment) $37-\mathrm{GHz}$ TB. The black points on each image trace the same TP coordinates as shown in Fig. 6, as 


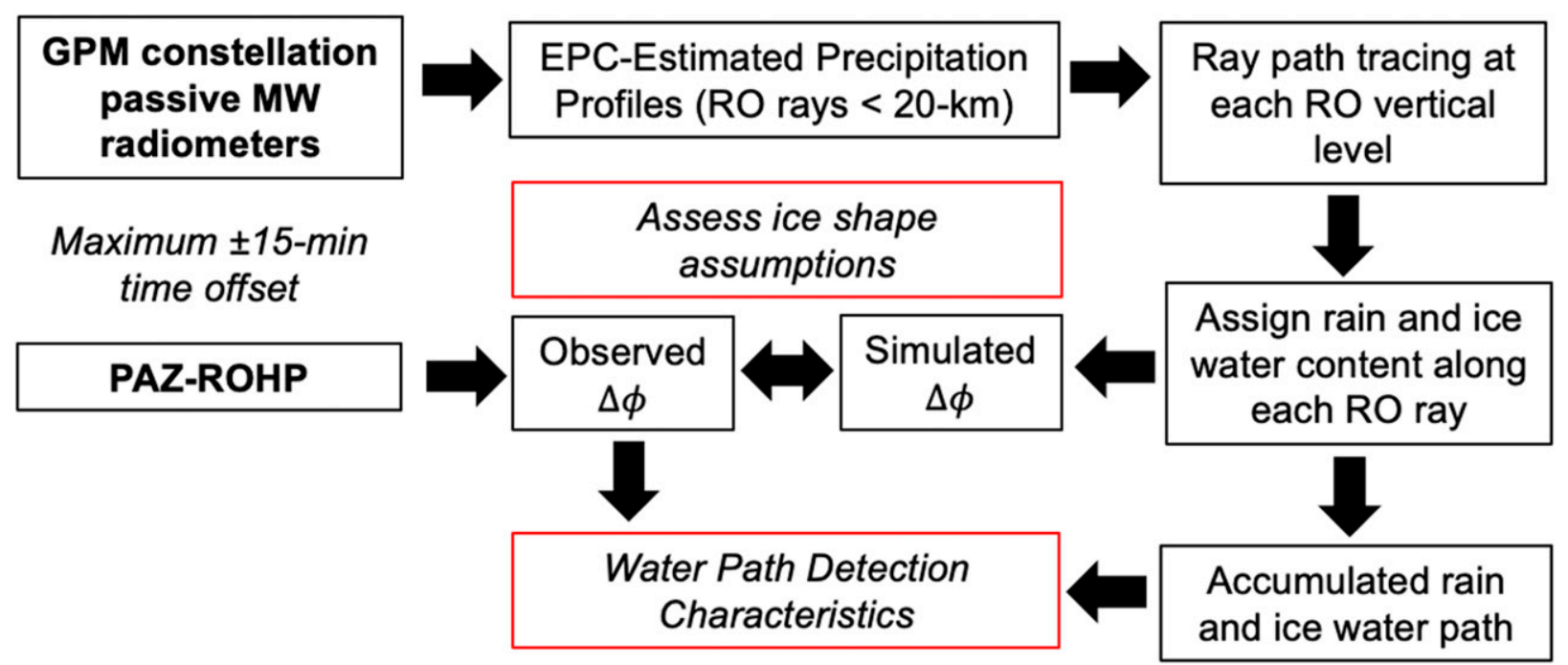

FIG. 5. Flow diagram of the procedure followed to forward-simulate the ROHP observations, to assess the capability to detect the total condensed water path, and the assumptions used for modeling the aspherical rain and ice hydrometeors.

the RO sets through the clouds. In this example, the uppermost rays slice through an area where the $37-\mathrm{GHz}$ TB $>260 \mathrm{~K}$ and $91-\mathrm{GHz} \mathrm{TB}<220 \mathrm{~K}$. These are TB signatures indicative of precipitation over ocean from clouds that have glaciated (i.e., have a developed ice phase above the freezing level). At $90 \mathrm{GHz}$ or higher, the TB provides little direct information on the near-surface precipitation structure. At these high frequencies the TB radiometric cooling arises from scattering of the upwelling rain emission by the high-albedo ice layer, more representative of cloud-top processes (Haddad et al. 2017). As the rays set to lower levels, the ray path moves outside of this area toward the edge where $37-\mathrm{GHz} \mathrm{TB}$ is radiometrically cooler (near $220 \mathrm{~K}$ ) and $91-\mathrm{GHz} \mathrm{TB}$ is radiometrically warmer (near $270 \mathrm{~K}$ ). These are TB signatures associated with precipitation, but with a less-developed ice phase.

The four panels in Fig. 8 depict the vertical cross section of the condensed water content profile (essentially a "slice"
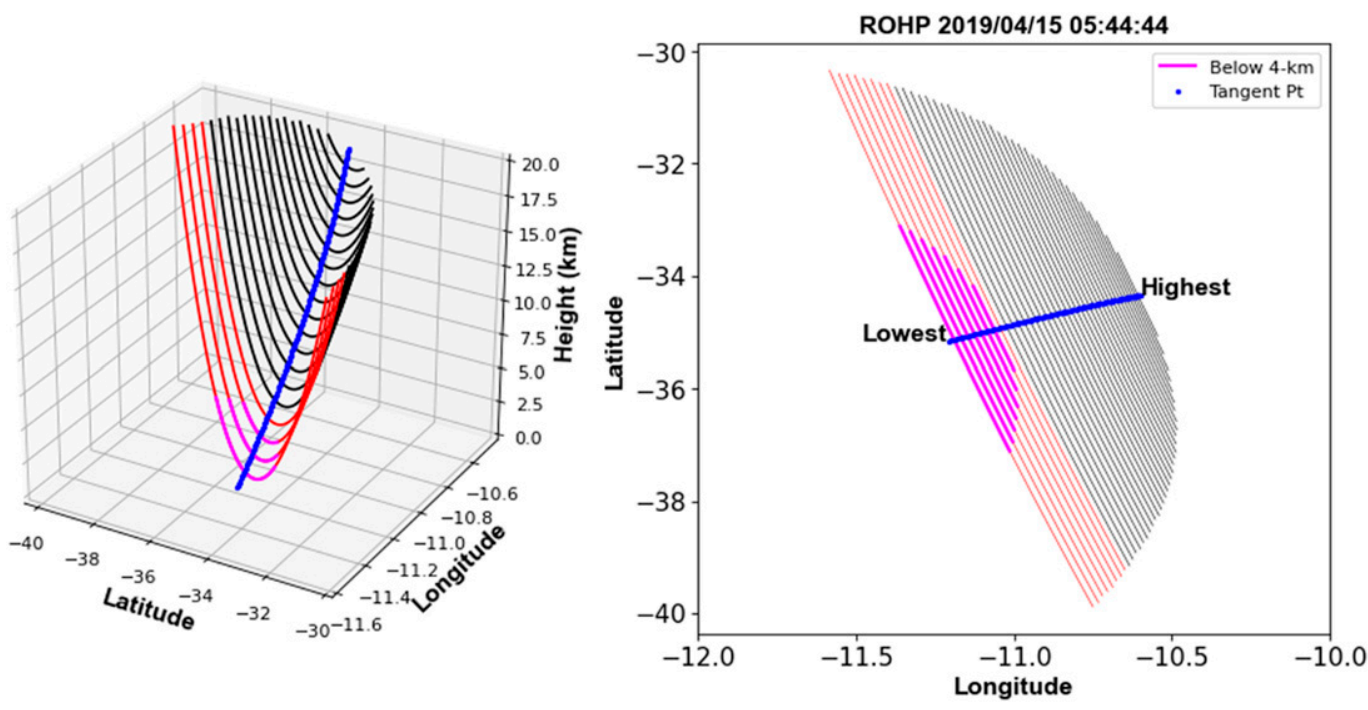

FIG. 6. Geometry of a ROHP RO near $\left(35^{\circ} \mathrm{S}, 11^{\circ} \mathrm{W}\right)$ at 0544 UTC 15 Apr 2019, as the rays set from top (highest levels) to bottom (lowest levels). Only the portion of the rays whose lowest elevation is below $20 \mathrm{~km}$ MSL are shown. The locations of nearest-to-surface tangent point (TP) coordinates are shown with blue symbols. Rays that fall below $4 \mathrm{~km}$ (anywhere) are red; of these, the portion of these rays that falls below $4 \mathrm{~km}$ is highlighted in magenta. Only every fifth ray is shown for clarity. (left) Three-dimensional view. (right) Two-dimensional projection at the surface. 

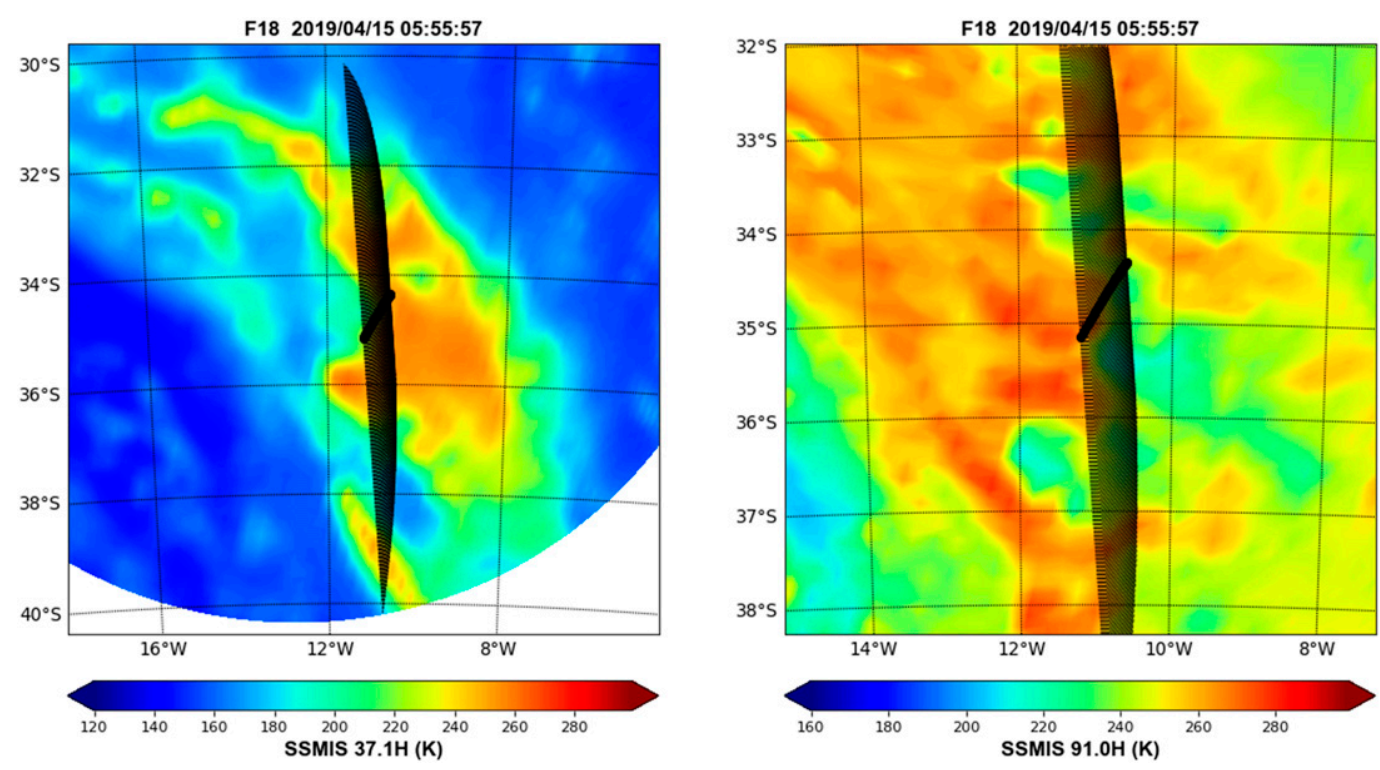

FIG. 7. DMSP F-18 overpass near 0555 UTC 15 Apr 2019 in the southern Atlantic Ocean from the SSMIS (left) 37.1-and (right) $91-\mathrm{GHz}$ channels. The set of parallel black lines represent the portion of the ray path as the RO sets, through the troposphere from $20 \mathrm{~km}$ down to the surface. The black dot along each line represents the RO tangent point for each of the rays.

through the 3D precipitation structure) underneath four rays (black line), whose lowermost TP height is at 8, 6, 4, and $2 \mathrm{~km}$ above the surface. Note the scale on the $x$ axis, which represents the along-ray-path distance, extends as long as $800 \mathrm{~km}$. While the majority of the ray-path bending occurs below $4 \mathrm{~km}$ where the majority of water vapor is concentrated, the polarimetric contribution to $\Delta \phi$ can occur anywhere along the rays wherever a region of liquid or ice water content is intercepted. In this example, for the ray at the $2-\mathrm{km}$ tangentpoint height (Fig. 8d), the rays passed through a region of condensed water about $500 \mathrm{~km}$ in extent. If very tall convection happened to be located near the beginning and/or end of the propagation paths shown in Fig. 8 (rather than being concentrated near the TP), contributions to $\Delta \phi$ could be induced along even longer ray-path segments. The $\Delta \phi$ profile is influenced by the vertical and horizontal locations of the precipitation during the occultation time. The ray tracer is not exact, and in some instances fails to converge at lower levels where strong refractivity gradients occur (Ao et al. 2012), necessitating an extrapolation to represent the rays in these levels.

To replicate the observing conditions that are associated with each ray in the existing $\operatorname{ROHP}(T, p, q)$ profile, the associated condensed water content $M\left(\mathrm{~g} \mathrm{~m}^{-3}\right)$ intercepted by each ray path is accumulated. Each ray is broken into $N 5-\mathrm{km}-$ long segments. Using the freezing level provided by MERRA-2, the path-integrated condensed water content can be separated into its liquid contribution (rainwater path, or RWP) and frozen (ice water path, or IWP):

$$
\mathrm{RWP}=\sum_{i=1}^{N} M_{i} d_{i} \quad\left(\text { when } T_{\mathrm{i}}>273 \mathrm{~K}\right),
$$

$$
\mathrm{IWP}=\sum_{i=1}^{N} M_{i} d_{i} \quad\left(\text { when } T_{\mathrm{i}}>273 \mathrm{~K}\right)
$$

where the subscript $i$ refers to each 5-km segment. Using a specific differential phase shift $K_{\mathrm{dp}}-M$ relation (mentioned here, but discussed in the next section), the simulated $\Delta \phi$ was also computed:

$$
\Delta \phi=\sum_{i=1}^{N} k_{\mathrm{dp}, i} d_{i}
$$

The procedure is repeated for each ray, down to the lowest level above the surface. In Fig. 9a, the blue and red lines indicate the vertical profile of RWP and IWP (units of $\mathrm{kg} \mathrm{m}^{-2}$ ), respectively. It is noted that by virtue of the long ray-path distance passing through the limb of Earth's troposphere, these values can be considerably larger (exceeding $50 \mathrm{~kg} \mathrm{~m}^{-2}$ in many heavy precipitation cases) than what are typical for a near-nadir-viewing radiometer. Below $2 \mathrm{~km}$, IWP drops off quickly owing to the sharp transition of the occulting ray paths outside of the area where the SSMIS 91-GHz TB $<220 \mathrm{~K}$.

Figure $9 \mathrm{~b}$ shows the corresponding ROHP-observed $\Delta \phi$ profile (maroon line), which increases beginning near $10-\mathrm{km}$ altitude, reaching a maximum of near $12 \mathrm{~mm}$ just below the freezing level (the simulated $\Delta \phi$ is also plotted; discussed below). Owing to ray-tracing errors and the maximum \pm 15 -min time offset between ROHP and the passive MW radiometers, analysis of one example is not very meaningful. To assess the capability to estimate the total water path $(\mathrm{TWP}=\mathrm{RWP}+\mathrm{IWP})$ from the observed $\Delta \phi$ profile, all 7929 ROHP datasets were analyzed in a diagnostic sense, to estimate TWP detection thresholds (and the expected error) based on $\Delta \phi$. 

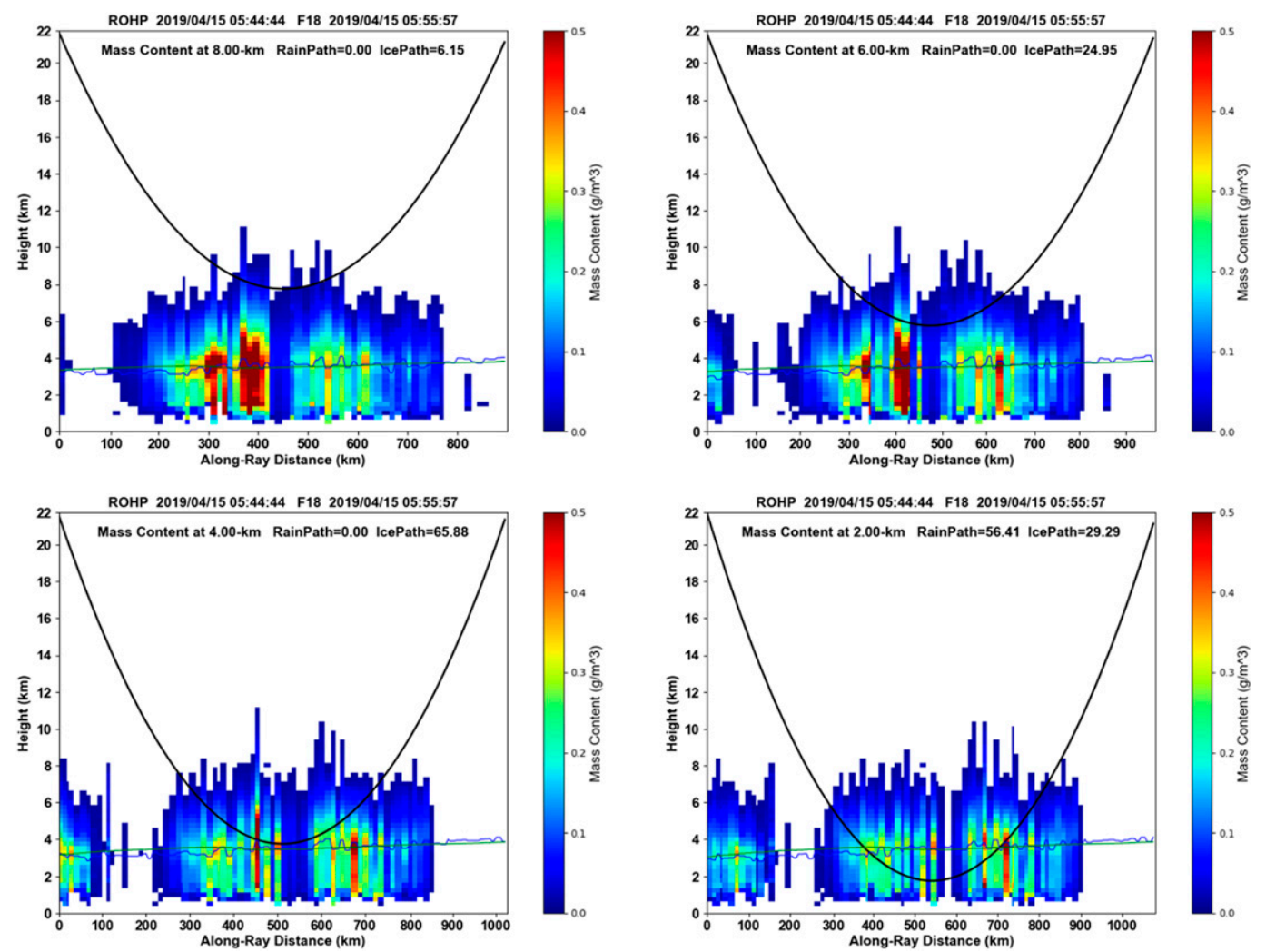

FIG. 8. Vertical profiles (along ray vs height) of the EPC-estimated condensed water content $\left(\mathrm{g} \mathrm{m}^{-3}\right)$ from the SSMIS data shown in Fig. 7, shown for the ROHP rays whose tangent points are (left to right from upper left) at vertical heights of $8,6,4$, and $2 \mathrm{~km}$. The solid black line indicates the associated ray path. The green horizontal line near 5-km height indicates the freezing level taken from the NASA MERRA-2 (M2) dataset; the blue line is the freezing level estimated by the EPC retrieval. The text indicates the along-ray-path integrated water content $\left(\mathrm{kg} \mathrm{m}^{-2}\right)$ for rain and ice, using the MERRA-2 freezing level for separation.

Figure 10a shows the relative operating characteristics (ROC) for detection of TWP exceeding 5,10, 20, and $30 \mathrm{~kg} \mathrm{~m}^{-2}$, using all ROHP rays that passed quality checks regardless of temperature conditions (43456 total rays). A ROC curve indicates the performance of a binary classifier as a discrimination threshold is varied. For this type of metric, the optimal performance is reached at the threshold point where the curve is closest to the upper left corner. For example, by setting the $\Delta \phi$ discrimination threshold at $2.9 \mathrm{~mm}$ (blue line), the associated TWP exceeds $10 \mathrm{~kg} \mathrm{~m}^{-2}$ with a probability of detection and false alarm rate of 0.7 and 0.3 , respectively. If the measured $\Delta \phi$ is larger than this, the probability of detection increases, but so does the false alarm rate.

Figure $10 \mathrm{~b}$ displays the same, but only includes the rays that are above the freezing level (i.e., RWP $=0$ ). For these ice-only conditions, the ROC performance is slightly improved (curves shift more to the upper left, compared to Fig. 10a). One explanation is that there is more variability in the relative contribution to $\Delta \phi$ from the liquid and ice phases for the rays that pass through both types of precipitation. This suggests that polarimetric RO has potential for detecting the uppermost height reached by convective precipitation and its associated intensity (Padullés et al. 2021).
These findings quantify the decision characteristics whereby the measured ROHP $\Delta \phi$ can be used as a discriminant to detect the presence of precipitation associated with the routine $\mathrm{RO}(T, p, q)$ products. Obviously, these results are predicated upon the level of accuracy of the EPC products themselves. Nevertheless, such information may be useful for assessment of numerical weather prediction models. While RO bending angle data are routinely assimilated into NWP models, the $\Delta \phi$ observable is an independent metric. It could inform the data assimilation system whether the RO that was being assimilated was associated with heavy precipitation conditions somewhere along the ray path. With sufficient sampling density, such information could guide toward improved positioning of the heavy precipitation (Aonashi and Eito 2011). As a diagnostic, $\Delta \phi$ has potential utility for model output statistics, to assess the model capability in timing and location the heavy precipitation where high moisture content and/or moisture gradients are present.

\section{b. Assessment of ice hydrometeor shape assumption}

To simulate $\Delta \phi$ along each ray, the associated rangederivative $K_{\mathrm{dp}}$ in (3) needs to be specified. A simplified approach is taken following Cardellach et al. (2018). If a 5-km 

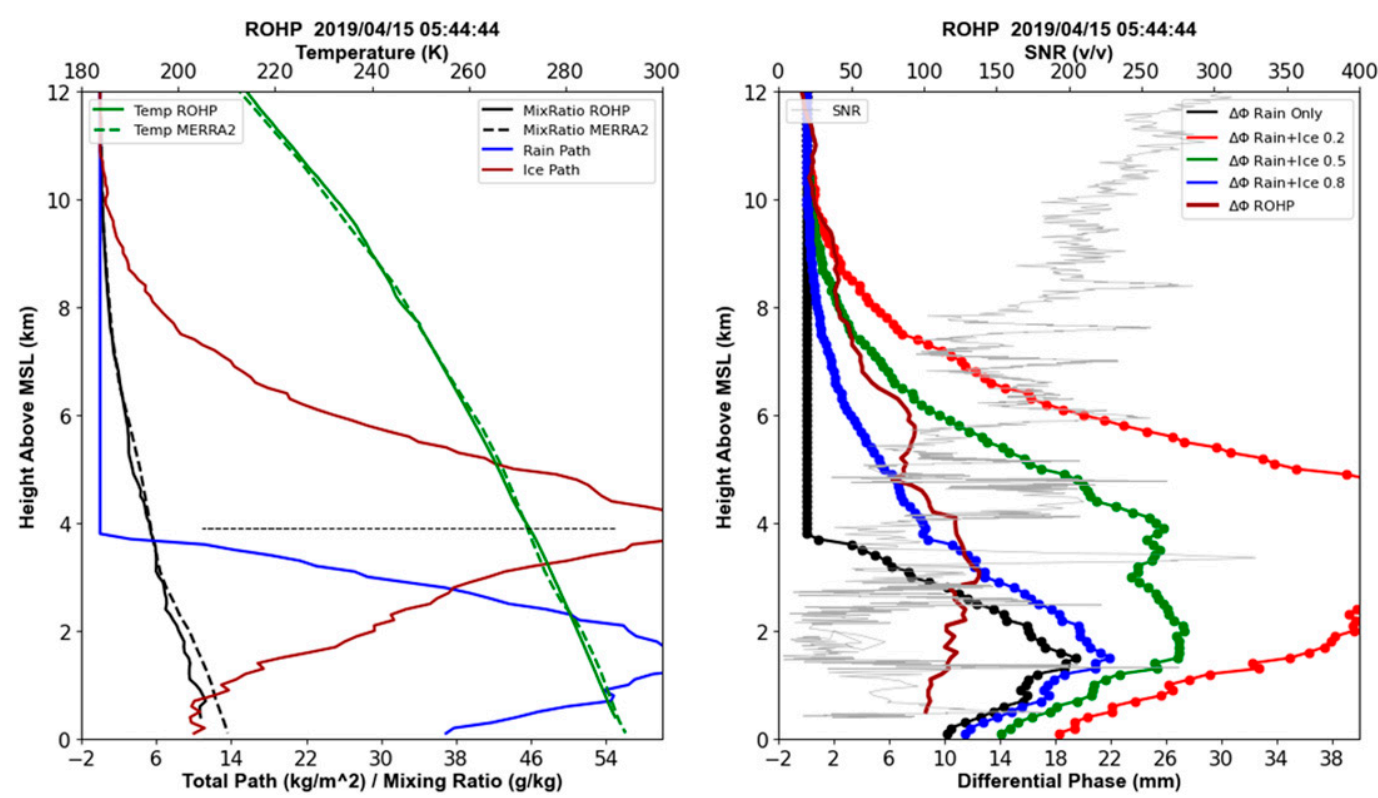

FIG. 9. (left) Vertical profile of the ROHP-retrieved temperature (solid thick green line) and mixing ratio (solid thick black line), alongside the profile of the EPC-estimated ray path-integrated liquid (blue line) and ice (red line) water content $\left(\mathrm{kg} \mathrm{m}^{-2}\right)$, retrieved from the SSMIS data in Fig. 7. The vertical axis extends to $12 \mathrm{~km}$. The lower horizontal axis is shared for the integrated water path $\left(\mathrm{kg} \mathrm{m}^{-2}\right)$ and the ROHP mixing ratio $\left(\mathrm{g} \mathrm{kg}^{-1}\right)$. For comparison, the temperature and mixing ratio interpolated from MERRA-2 are shown with the associated dashed green and black lines, respectively. (right) As in the left panel, but showing the ROHP measured $\Delta \phi$ (maroon line), alongside the simulated $\Delta \phi$ assuming rain below the freezing level and three different shape assumptions on the ice above the freezing level. The blue, green, and red lines indicate ice with an axis ratio of $0.8,0.5$, and 0.2 , respectively. For comparison, the black line represents the case where any condensed water above the freezing level is set to zero. The shaded gray line indicates the decrease in the ROHP signal to noise level as the occultation sets.

segment $M_{i}$ was associated with $T_{i}>273 \mathrm{~K}$, the media was assumed to be liquid (rain) phase. The rain hydrometeor size distribution is specified using the parameterization developed by Haddad et al. (1997), which is appropriate for tropical rainfall and provides statistically independent size distribution parameters. The rain hydrometeors are modeled by horizontally oriented oblate spheroids with an axis ratio (defined here as the ratio of the minor $a$ to major axis $b$ ) specified using the relation developed by Beard and Chuang (1987). The T-matrix method (Mischenko et al. 1997) was used to calculate L-band $(\sim 1.4 \mathrm{GHz})$ forward-scattered field amplitudes and phases, and $K_{\mathrm{dp}}$ was tabulated at discrete intervals over a large range of mass content $M$. At L band, even the heaviest rain rates are largely dominated by Rayleigh scattering and $K_{\mathrm{dp}}$ is essentially proportional to the third moment of the particle size distribution. Therefore, $K_{\mathrm{dp}}$ scales nearly linearly with $M$ as shown in Fig. 11 (solid black line). (For reference, a rain media of mass content $1 \mathrm{~g} \mathrm{~m}^{-3}$ is equivalent to $\sim 25 \mathrm{~mm} \mathrm{~h}^{-1}$ rain rate.) For ease of understanding, Fig. 11 also shows the associated ray pathlength that would be needed to attain $\Delta \phi=10 \mathrm{~mm}$ (dashed black line). For a rain medium with $M=1 \mathrm{~g} \mathrm{~m}^{-3}, K_{\mathrm{dp}} \sim 0.4^{\circ} \mathrm{km}^{-1}$; at this intensity a $40-\mathrm{km}$ ray pathlength would yield $\Delta \phi=16^{\circ}$. Typically, GNSS phase delay is given in units of length; scaling by $\lambda / 2 \pi$ (where $\lambda=19 \mathrm{~cm}$ for the GNSS L1 carrier) yields $\Delta \phi=10 \mathrm{~mm}$.

Each 5-km segment $M_{i}$ that was associated with $T_{i}<273 \mathrm{~K}$ was assumed to be solid (ice) phase. Since these hydrometeors can take on wide variability in shape and habit, the simulations were repeated three times, using ice shapes represented by simple oblate spheroids with a fixed axis ratio of $0.8,0.5$, and 0.2 , assumed to be solid ice (density $=0.91 \mathrm{~g} \mathrm{~cm}^{-3}$ ). The plausibility of this assumption is explained in appendix B. The $K_{\mathrm{dp}}-M$ relations are shown in Fig. 11 . Note that an ice media with an axis ratio of 0.2 induces a larger $\Delta \phi$ than the massequivalent rain; the same $\Delta \phi=10 \mathrm{~mm}$ could have resulted if the ray passed through an ice media with $M=0.5 \mathrm{~g} \mathrm{~m}^{-3}$ along a $40-\mathrm{km}$ path. As shown above, when the ray paths fall below the freezing level the net $\Delta \phi$ may have contributions from both ice and rain. In this simulation, a stratiform melting or a convective mixed phase was not represented. The technique here is intentionally simplified; at this point making assumptions on the decision of how and where to mix the ice and liquid content, or introduce melting ice and the choice of the appropriate dielectric constant (Johnson et al. 2012; Galligani et al. 2013), would bring in additional levels of uncertainty and detract from the ability to ascertain first-order results.

Figure $9 \mathrm{~b}$ shows the results of these simulations for the ROHP example above. The observed $\Delta \phi$ agrees with the scenario whereby the ice axis ratio decreases with height; better agreement is noted with an axis ratio $=0.5$ above $6 \mathrm{~km}$, but with an axis ratio $=0.8$ from 3 to $5 \mathrm{~km}$. Below $2 \mathrm{~km}$, IWP drops off quickly (Fig. 9a) owing to the sharp transition of the occulting ray paths outside of the area where the SSMIS $91-\mathrm{GHz}$ 

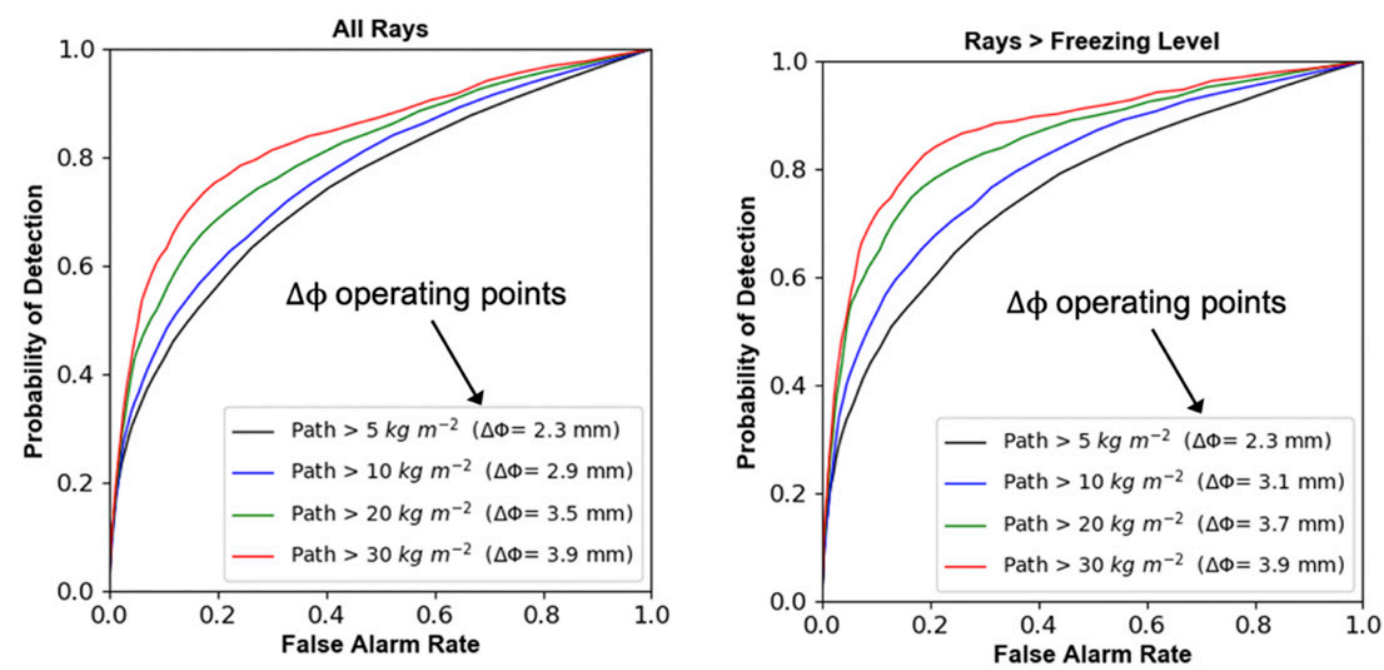

FIG. 10. (left) The relative operating characteristic (ROC) characteristic curves for estimation of four different threshold levels of the total (rain + ice) condensed water path from the ROHP measured $\Delta \phi$. The operating point indicates the $\Delta \phi$ value at which the performance is optimized (i.e., the curve is closest to the upper-left corner). A total of 43456 ROHP rays were used. (right) As in the left panel, but only for the rays above the freezing level (25833 rays total).

TB $<220 \mathrm{~K}$ noted above. Below $3 \mathrm{~km}$, even an assumption of no ice (IWP forced to zero everywhere, black line in Fig. 9b) along the ray paths overestimates the simulated $\Delta \phi$.

This particular example is shown to highlight uncertainties and ambiguities associated with simulating individual PRO profiles and the interpretation of $\Delta \phi$ in terms of the ice asphericity. Since the EPC utilizes the CORRA profile products, any uncertainty induced by size distribution assumptions in that algorithm carries over into the EPC profile estimates. Even with ideal knowledge of the microphysics, the largest source of uncertainty arises from the fine-scale nature of the $\mathrm{RO}$ as it sets through the precipitation structure. Given the narrow (1-km or so) across-ray resolution of the GNSS signals, any offset or misplacement of the simulated ray paths can give rise to a different value of the simulated $\Delta \phi$, especially near edges of clouds or other sharp gradients in the cloud structure. The ray-tracing models do not account for horizontal variations in refractivity which can lead to tangent point drift and therefore induce uncertainty in the computed ray-path locations (Foelsche et al. 2011). Furthermore, the precipitation state and position evolve during the allowable \pm 15 -min time offset. These collective uncertainties underly the rationale for the simplified forward model. With these event-by-event uncertainties, the analysis is therefore done on a collective basis, using the same data presented in section $3 \mathrm{a}$.

Figure 12 shows the normalized histogram of the ROHP observed $\Delta \phi$ (thick black line), and the normalized histograms from each of the four simulations (the three ice axis ratio AR assumptions, and a no-ice assumption). Only the tail of the distribution is shown to highlight differences among these matched ROHP-passive MW events. The upper left (Fig. 12a) uses the same ROHP data (all rays) shown in Fig. 10a. In general, there is overall agreement between the ROHP observed and the simulated $\Delta \phi$ with the axis ratio $=0.5$ assumption until $\Delta \phi$ exceeds $7 \mathrm{~mm}$, after which better agreement is noted with an axis ratio of 0.8 and larger (i.e., less oblate ice). Including only rays that were always above the freezing level (same data as in Fig. 10b), similar agreement is noted with an axis ratio $=0.8$ is noted, but it extends to larger values of $\Delta \phi$ (Fig. 12b). Refining this scenario even further to include only rays, which never fell below the $T=253 \mathrm{~K}$ level (Fig. 12c), the agreement between the observed and simulated histograms

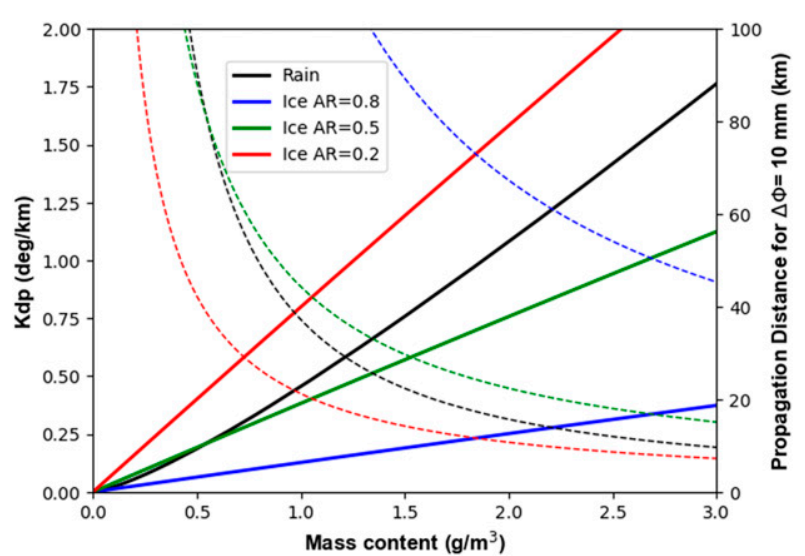

FIG. 11. One-way propagation differential phase shift $K_{\mathrm{dp}}\left({ }^{\circ} \mathrm{km}^{-1}\right.$, left axis) at $1.4 \mathrm{GHz}$, as a function of equivalent mass content $M\left(\mathrm{~g} \mathrm{~m}^{-3}\right)$. The blue, green, and red lines indicate an ice media characterized by oblate spheroids with axis ratios of $0.8,0.5$, and 0.2 , respectively, and black is for a rain media with axis ratio following Beard and Chuang (1987). The associated colored dashed lines indicate the propagation distance ( $\mathrm{km}$, right axis) through each of these media that would be required for a value of $\Delta \phi=10 \mathrm{~mm}$. 

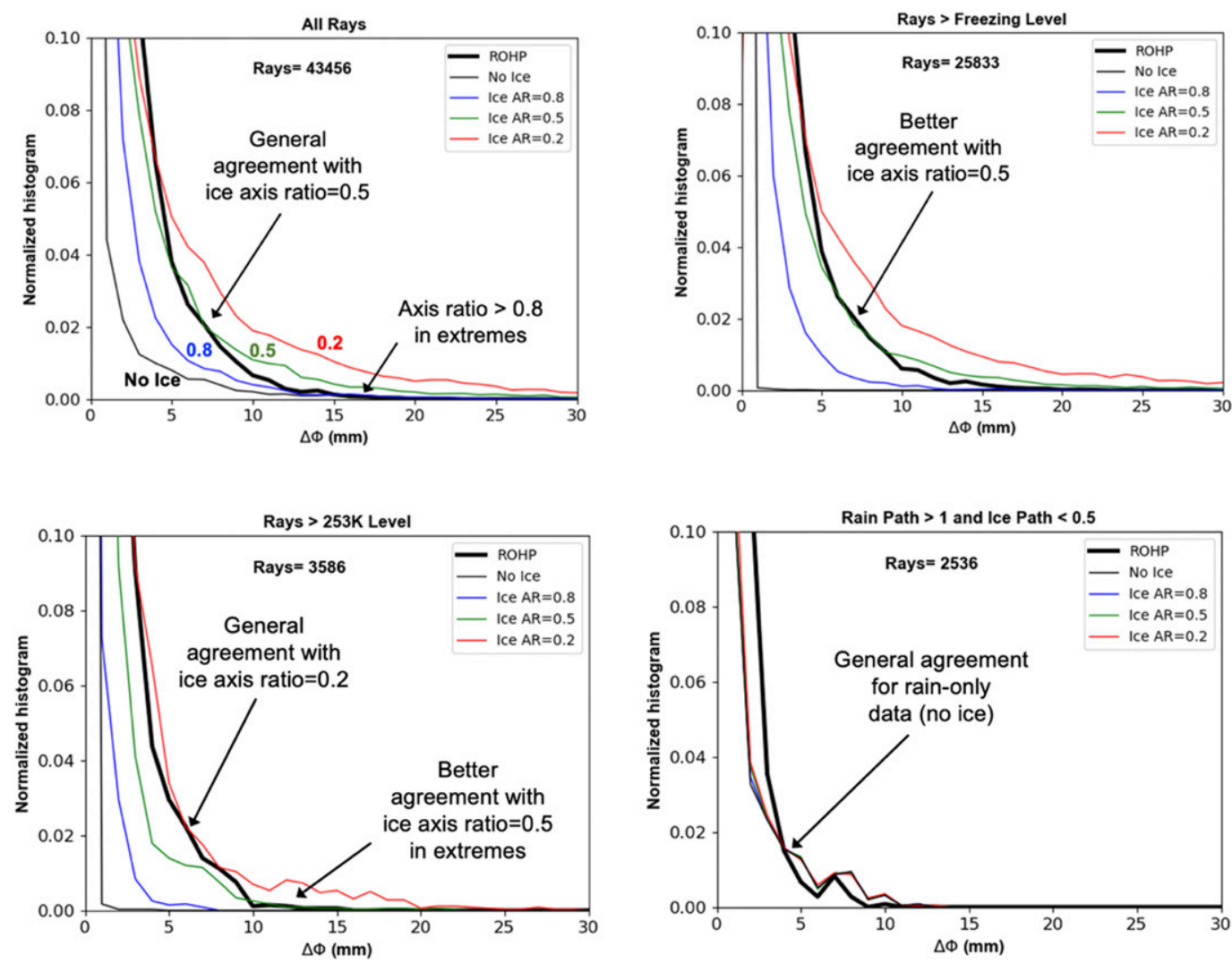

FIG. 12. Close-up of the tail of the normalized histogram of the observed ROHP $\Delta \phi$ (thick black line) and the corresponding simulated $\Delta \phi$ assuming the ice hydrometeor characteristics as in Fig. 10. The blue, green, and red lines indicate ice with axis ratios of $0.8,0.5$, and 0.2 , respectively. The black line represents the case where any condensed water above the freezing level is forced to zero. (top left) All rays (43 456 total). (top right) Only for rays above the $T=273 \mathrm{~K}$ level (25833 total). (bottom left) Only for rays above the $T=253 \mathrm{~K}$ level (3586 total). (bottom right) Only for rays that where RWP $>1 \mathrm{~kg} \mathrm{~m}^{-2}$ and IWP $<0.5 \mathrm{~kg} \mathrm{~m}^{-2}$ (very little ice) (2536 total).

occurs for an axis ratio of 0.2 until $\Delta \phi>8 \mathrm{~mm}$; after this value better agreement is noted for an axis ratio of 0.5 .

The discussion above has focused upon the axis ratio of the ice hydrometeors used in the $\Delta \phi$ simulations. However, the rays processed for Fig. 12a (all rays) pass through a variety of precipitating conditions, some with high RWP relative to IWP, and vice versa. To verify that the simulations of $K_{\mathrm{dp}}$ for the RWP portion of the TWP are indeed replicating what was observed, Fig. 12d shows the results where only rays that passed though nearly pure rain are processed. These were isolated by locating ROHP events where RWP $>1 \mathrm{~kg} \mathrm{~m}^{-2}$ and IWP $<0.5 \mathrm{~kg} \mathrm{~m}^{-2}$ (2536 rays). For these cases, there is general overall agreement between the shape and magnitude of the observed and simulated $\Delta \phi$ histograms, suggesting that the assumptions used in modeling the rain media are realistic.

These findings suggest that when the precipitation media traversed by the RO is pure rain, $\Delta \phi$ can be related to $M$ with little ambiguity by virtue of the nearly linear $K_{\mathrm{dp}}-M$ relation (appendix B). For other cases, the ROHP $\Delta \phi$ is sensitive to the asphericity of the ice hydrometeors in the $0.5-0.8$ range for the ray paths that traversed above the freezing level. This is in the range of the 0.6 value obtained by Matrosov et al. (2005) from analysis of dual-frequency airborne radar data. There is better agreement with flatter axis ratios (0.2-0.5 range) at higher levels $(T<253 \mathrm{~K})$ where the presence of a mixed phase is less likely. However, it is difficult to state more quantitative results since a melting or convective mixed phase was not included in these simplified model simulations, nor low-density ice and graupel.

Analysis of these ROHP data exhibit cases where very tall convection was captured, with significant $\Delta \phi$ well above $10-\mathrm{km}$ height. Figure 13 shows one example of this, from a ROHPGPM coincidence event near 0934 UTC 16 March 2019. The location is in southern Brazil (near $22^{\circ} \mathrm{S}, 56^{\circ} \mathrm{W}$ ) in a region where the largest thunderstorms on Earth are known to exist (Zipser et al. 2006). The ray paths passed through an area where GMI 166-GHz TB $<160 \mathrm{~K}$ (Fig. 13b), indicative of strong vertical air motion and likely presence of precipitationsized ice at these upper heights. Even the flattest axis ratio of 0.2 is unable to replicate the $\Delta \phi$ above 8 -km height (Fig. 13a). One explanation for this discrepancy is the presence of widespread aligned ice crystals in an upper-level anvil that has spread out near the tropopause, whose ice crystals are too weakly scattering to be detected by the DPR Ku- or Ka-band 

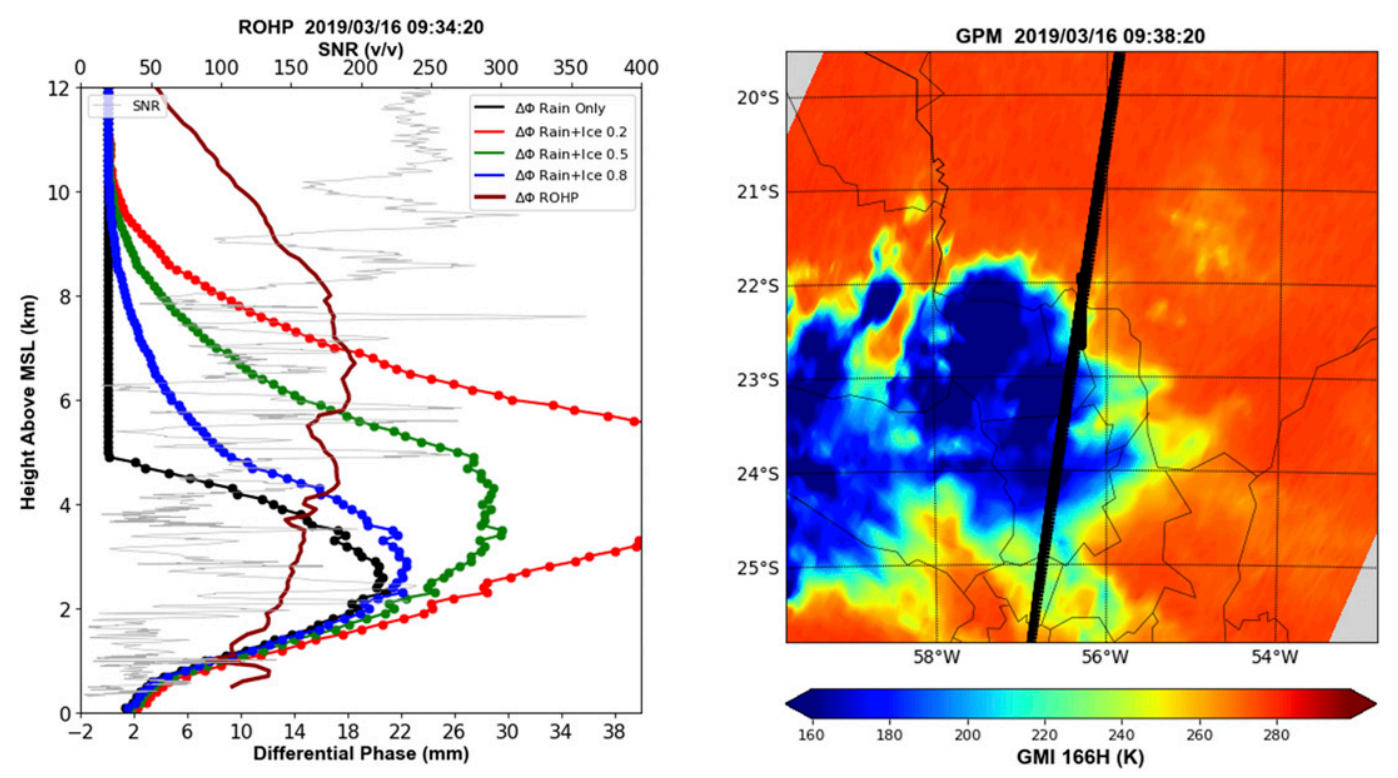

FIG. 13. ROHP-GPM coincidence event near 0934 UTC 16 Mar 2019. The location is in southern Brazil near $22^{\circ} \mathrm{S}$, $56^{\circ} \mathrm{W}$. (left) As in Fig. 9 (right). (right) As in Fig. 7 (right), but for the 166-GHz GMI TB.

radars. Since the EPC a priori information is taken from the DPR dual-frequency precipitation profile retrieval, the simulated $\Delta \phi=0$ in these regions. Quantitatively, this scenario is plausible; extrapolating Fig. 11, an axis ratio of 0.2 and water content of only $0.1 \mathrm{~g} \mathrm{~m}^{-3}$ along a $300-\mathrm{km}$ path can induce $\Delta \phi>10 \mathrm{~mm}$.

Physically, this explanation is supported by recent findings by Gong et al. (2020) that used the GMI 166-GHz channel polarization difference $(\mathrm{V}-\mathrm{H})$ capability. High polarization differences were found in cases with stratiform precipitation layers, indicative of horizontally aligned snow aggregates. More recently, Padullés et al. (2021) used a large collection of near-coincident GPM and CloudSat observations (providing a three-frequency radar dataset) (Turk et al. 2021) to simulate $\Delta \phi$ at $\mathrm{L}$ band. These experiments augmented the limited upper-level ice detection characteristics of DPR with the CloudSat radar, which is more sensitive to smaller ice particles. For the deep convective cases, the simulations replicated the high-level $\Delta \phi$ observed similar to Fig. 13. These $\Delta \phi$ signatures may be produced as a result of outflow from the anvil region of deep convective clouds, which spread smaller ice crystals across a thinner cirrus layer. However, since $\Delta \phi$ is a pathintegrated measurement, investigation of more ROHP data is needed to determine the sensitivity of the $\Delta \phi$ signature to the combination of particle size and path extent.

These polarimetric signatures represent forward scattering through ice at a $19-\mathrm{cm}$ wavelength, that is largely dominated by Rayleigh scattering, owing to the size parameter $a=\pi d / \lambda$ (where $d$ is the equivalent volume diameter) $<0.1$ whenever $d<7 \mathrm{~mm}$. Being a phase measurement, bulk discrimination among ice shape is expected, rather than to detailed shape properties such as needles, plates, and bullets. This is the rationale for simulating complex shapes by the equivalent inscribed ellipse and associated axis ratio. There are abundant publications detailing simulations of active and passive polarimetric signatures of ice crystals at millimeter wavelengths, for simulating observations expected from the MetOp-SG Ice Cloud Imager (ICI) (Wang et al. 2017) and future 94-GHz and higher cloud radars (Battaglia et al. 2020). Even with the difference in viewing geometry, this wide frequency disparity of the PRO measurements can provide a path-integrated constraint that can be used to refine or constrain the type and location of precipitation-sized upper-level ice. This inference on precipitation water path at lower levels can be viewed as complementary to the ice path estimates provided by the long record of Microwave Limb Sounder (MLS) observations of cloud ice (Waliser et al. 2009). MLS operates in similar wavelength ranges to the future ICI (Wu et al. 2009), sensitive to cloud ice that (unless the propagation path is very long), is more or less invisible to ROHP.

\section{Separation of ROHP moisture profiles by the topmost $\Delta \phi$ level}

Recent findings from analysis of coincident in situ observations of moisture and precipitation in the tropics have noted that the occurrence of mesoscale deep convection, including mesoscale convective systems, is strongly coupled to the structure of the lower free-tropospheric (LFT; defined as the 700-900-hPa layer) humidity (Schiro and Neelin 2019). These findings suggest further examination to assess this relationship more globally. Figure 2 indicated that the column-averaged $\Delta \phi$ served as an effective proxy for the surface rain rate. The example in Fig. 9 shows that the topmost height of the condensed water and the associated $\Delta \phi$ profile reaches (assuming a $1 \mathrm{~kg} \mathrm{~m}^{-2}$ and 3-mm threshold, respectively) a similar level above the freezing level, near $10 \mathrm{~km}$. If a similar relation can be noted from a large collection of ROHP data, this would 


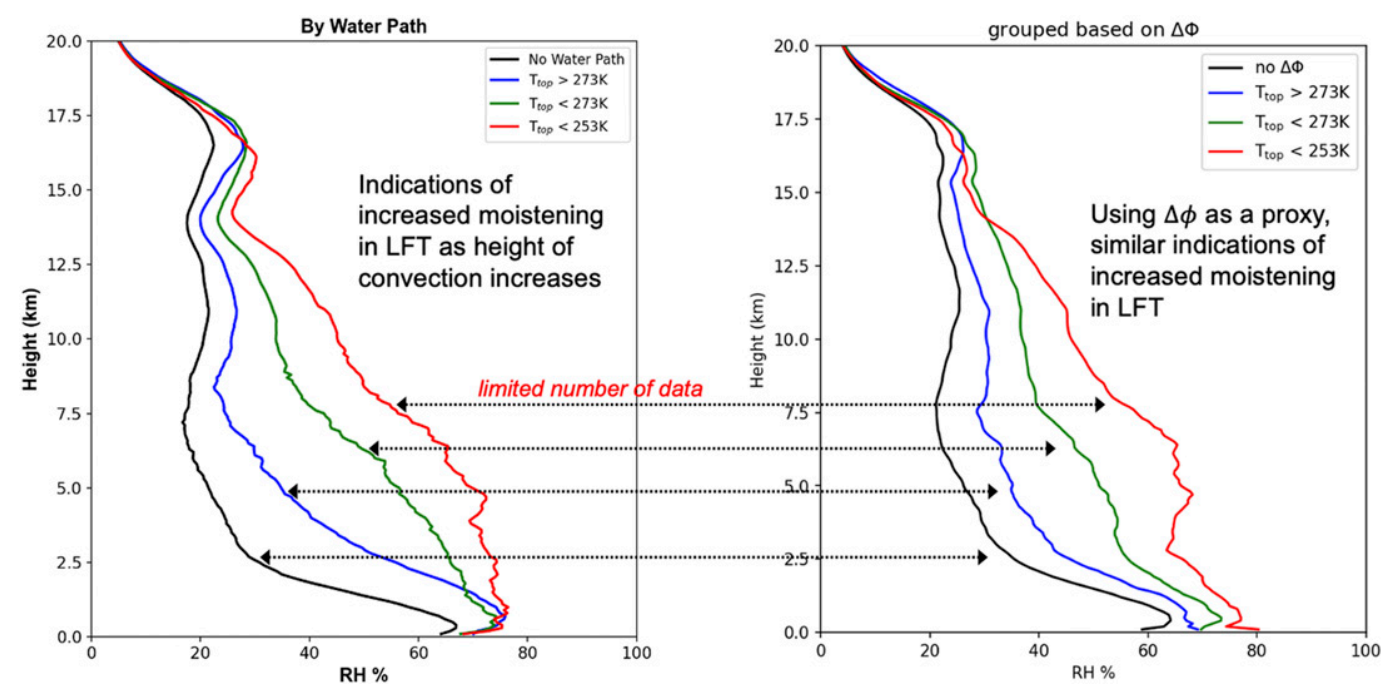

FIG. 14. (left) Average ROHP relative humidity profile for all data, separated by the topmost height where the EPC-estimated total water path first exceeded $1 \mathrm{~kg} \mathrm{~m}^{-2}$, colored to identify profiles where the topmost height was below the $T=273 \mathrm{~K}$ level (blue line), profiles where the topmost height was above the $T=273 \mathrm{~K}$ level (green line), and profiles where the topmost height was above the $T=253 \mathrm{~K}$ level (red line). Profiles where no water path was estimated are shown with the black line. (right) As in the left panel, but the profiles are separated by the topmost height where $\Delta \phi$ first exceeded $3 \mathrm{~mm}$. Profiles where no $\Delta \phi$ was observed are shown with the black line. For the $T=$ $253 \mathrm{~K}$ level threshold, limited data are available (93 and 32 profiles for the left and right panels, respectively).

imply that $\Delta \phi$ could serve as a proxy to separate profiles by the strength of the vertical air motion, revealing details of the role of the LFT moisture. An analogy is noted with the use of the topmost height reached by GPM DPR dual-frequency observations associated with intense convective precipitation system with a substantial amount of ice aloft (Iguchi et al. 2018).

To examine, the same collection of these ROHP data within $\pm 30^{\circ}$ latitude is separated into four categories. The first category contains the profiles where no total water path (using the $1 \mathrm{~kg} \mathrm{~m}^{-2}$ threshold) was estimated along any rays in the RO profile, which are termed nonconvective conditions. The second category contains the profiles where the topmost height exceeding this threshold was below the $T=273 \mathrm{~K}$ level, i.e., no deep convection and any rain would be from warm-rain processes. The third and fourth categories contain the profiles where the topmost height is above the $T=273$ and $253 \mathrm{~K}$ levels, respectively. These categories effectively divide deep convection by depth, with the latter category being stronger deep convection. Figure 14a shows the average ROHPobserved relative humidity $(\mathrm{RH})$ profiles associated with each of these four categories. The rain-free cases exhibit $\mathrm{RH}<30 \%$ in the LFT (Romps 2014), with increased moistening in this layer as the topmost height increases (bluegreen-red lines).

Figure $14 \mathrm{~b}$ presents these same data, but using the ROHPobserved $\Delta \phi$ to separate the profiles. While the same dataset is used for both panels, the separation criteria are independent from one another, Figs. 14a and 14b being prepared solely from simulations and observations, respectively. While there are some differences with the corresponding profiles in Fig. 14a in the lowest $1 \mathrm{~km}$, there is a general agreement in the level of increased moistening between the 3 - and $10-\mathrm{km}$ levels.
While limited data are available for data above the $T=253 \mathrm{~K}$ level (red line), this encouraging finding suggest there is utility for the use of the $\Delta \phi$ profile above the freezing level to separate convective transition statistics or for other model assessments, such as assumptions of convective parameterization schemes (Murphy et al. 2019), or misrepresentation of moisture under convective conditions (de la Torre-Juárez et al. 2018).

Considerable value could be added to these observations if a series of identical, near-contemporaneous observations could also be taken in the surrounding environment, thereby enabling comparison to be made with the distributions of the LFT moisture. This is the science motivation behind the polarimetric RO constellation concept (Turk et al. 2019; see appendix A). If the moist LFT environment is controlling convective precipitation, then convective transition statistics of precipitation conditioned on the nearby LFT environment should be close to each other. Conversely, if convective transition statistics of precipitation conditioned on the nearby LFT environment exhibit no strong relationship, this would indicate that other processes (e.g., moistening of the LFT from nearsurface convergence) are influencing factors.

\section{Conclusions}

In this investigation, a 2-yr collection of level-2 data (temperature $T$, pressure $p$, moisture $q$, and polarimetric phase $\Delta \phi$ ) from the Radio Occultations through Heavy Precipitation (ROHP) technology demonstration mission were analyzed. Since $\Delta \phi$ is a path-accumulated measurement and does not explicitly resolve the precipitation structure along each propagation ray path, these ROHP data were complemented by near-simultaneous observations from the GPM passive MW 
radiometer constellation. The passive MW data from GMI and the $F$ - 18 SSMIS were inverted into profiles of condensed water content across the radiometer swath, using the emissivity principal component (EPC) precipitation profiling technique. A ray-tracing method was used to propagate the vertically spaced rays from each ROHP event through the resultant precipitation structure. This provided a nearly $8000 \mathrm{RO}$ events to compare simulated and observed $\Delta \phi$ profiles, covering a global range of precipitation type and intensity. The results are summarized in three topic areas:

1) Relative operating characteristics were performed to relate the observed $\Delta \phi$ to exceedance of a ray-path-accumulated condensed water content (regardless of ice and/or water phase). Probability of detection and associated false alarm ratio levels of 0.7 and 0.3 , respectively, are typical for path totals exceeding $20 \mathrm{~kg} \mathrm{~m}^{-2}$. These detection characteristics are improved when the events were restricted to the rays that propagated above the freezing level, indicating better detectability to large upper-level ice-phase hydrometeors.

2) Further investigation the $\Delta \phi$ signal was carried out by $\Delta \phi$ profile simulations, using known oblate-shaped rain hydrometeor and simplified ice crystal shapes below and above the freezing level, respectively. For the ray paths that traversed above the freezing level, the best agreement between simulations and observations was noted for ice hydrometeor shapes with an equivalent axis ratio in the $0.5-0.8$ range, with better agreement with flatter axis ratios $(0.2-0.5$ range $)$ at higher levels $(T<253 \mathrm{~K})$. While these axis ratio trends are in range of other published works, it is difficult to state more quantitative results since a melting or convective mixed phase was not included in these simplified model simulations, nor low-density ice and graupel. These simulations indicate that possible inferences on the icephase hydrometeor asphericity can be discerned from the PRO $\Delta \phi$ signal, such as separation of upper-level pristine ice from irregularly shaped graupel below.

3) To examine the use of $\Delta \phi$ for examining moistening of the lower free troposphere, the ROHP relative humidity profiles from this same dataset were analyzed, by separating the profiles into categories representative of the increasing topmost vertical level noted in the water path estimates. This same separation also was done solely using the ROHPobserved $\Delta \phi$. A general agreement was noted in the level of increased moistening between the 3 - and $10-\mathrm{km}$ levels, indicating that the $\Delta \phi$ profile above the freezing level may serve as an effective proxy to directly separate $\mathrm{RH}$ profiles for convective transition statistics, and to discriminate the polarimetric RO in the closely spaced constellation measurement proposed in Turk et al. (2019).

To date, ROHP is the only source for space-based polarimetric RO data, yielding $\sim 200$ RO per day. Adaptation of existing CubeSat-sized RO receivers for orthogonal receive capability coupled to polarized antennas sized for opposing sides of a CubeSat (to capture fore and aft occultations) offer a relatively low-cost means to expand this quantity. These polarimetric RO data could be analyzed in proximity with other small-satellitebased Earth science investigations (Stephens et al. 2020a).
Rapidly evolving technologies provide the capability to host scanning passive microwave (MW) sounders (Blackwell et al. 2018), and Ka- and W-band radars (Sy et al. 2021; Stephens et al. 2020b; Battaglia et al. 2020) on small low-Earth-orbiting (LEO) satellite platforms. However, aspects of the techniques presented in section $3 \mathrm{a}$ are useful with existing nonpolarimetric RO data. For example, the upcoming six-satellite TimeResolved Observations of Precipitation structure and storm Intensity with a Constellation of Smallsats (TROPICS) observatory (Blackwell et al. 2018) will provide abundant opportunities for passive MW coincidences with the COSMIC-2 satellites within the tropical latitudes.

These simulations are essentially a basic demonstration of a polarimetric RO forward operator to simulate the depolarization induced by the precipitation-sized media. While RO forward operators that simulate the bending angle are used at operational weather centers (Ruston and Healy 2021), currently no capability exists to simulate the differential propagation phase delay simultaneously with the RO bending angle. Even without this capability, the $\Delta \phi$ signal can be used independently, for example, to assess a model capability in timing, location, and structure of the forecasted heavy precipitation, in areas where high moisture content and moisture gradients are present (Lasota et al. 2018).

Acknowledgments. The work conducted at ICE-CSIC/IEEC was supported by the Spanish Grant ESP2015-70014-C2-2-R. The research was funded by the Spanish Ministry of Science, Innovation and Universities Grant RTI2018-099008-BC22/AEI/10.13039/501100011033/FEDER, EU. The contribution from EC has been partially supported by the Radio Occultation Meteorology Satellite Application Facility (ROM SAF) which operated under the auspices of EUMETSAT. The JPL authors acknowledge support from the NASA U.S. Participating Investigator (USPI) and Geodesy program elements. JDN is supported in part by National Science Foundation Grant AGS-1936810. The technical discussions with Drs. Jie Gong and Dong $\mathrm{Wu}$ are gratefully acknowledged. This work was carried out at the Jet Propulsion Laboratory, California Institute of Technology, under a contract with the National Aeronautics and Space Administration.

Data availability statement. ROHP data are acquired from the Paz satellite. The ROHP demonstration is a collaboration between ICE-CSIC/IEEC, Hisdesat, NOAA, UCAR, and JPL. ROHP data are available at https://paz.ice.csic.es. COSMIC-2 data are available from the COSMIC Data Analysis and Archive Center (CDAAC). GPM level 1C passive MW radiometer data are openly available via the Precipitation Processing System (PPS) at NASA Goddard Space Flight Center.

\section{APPENDIX A}

\section{Closely Spaced RO Satellite Constellation}

The infrequent occurrence of heavy precipitation presents a challenge for using RO data to assess moisture structure in and near individual convective precipitation events, since RO 
occurrences are too infrequent and spatially distributed for this purpose. RO constellation orbits are typically configured to homogenize the sampling density, (e.g., COSMIC-2 provides about 5-10 RO's per $1^{\circ}$ grid box per month). For example, the ray paths associated with an $\mathrm{RO}$ may have traversed through an edge of a convective cloud system, not necessarily indicative of the moisture structure within the convective region associated with strong vertical air motion. The polarimetric RO discussed in this manuscript provides an indication that precipitation was intercepted, but no contextual information.

RO data are often dismissed as having an "along-ray" resolution too coarse for purposes of investigating the moisture structure associated with heavy precipitation. In the troposphere, the RO has very fine-scale resolution of $\sim 1 \mathrm{~km}$ in the "across-ray" direction, primarily determined by the effective Fresnel zone. Coupled with its innate fine-scale vertical structure, an RO observation possesses subkilometer resolution in two of the three spatial dimensions. For any single RO observation, these characteristics are not especially useful since a larger-scale horizontal context is not provided.

An earlier study by the authors (Turk et al. 2019) considered a closely spaced ( $\sim 2$-min separation) small-satellite constellation hosting polarimetric RO receivers originally designed for the Community Initiative for Continuing Earth Radio Occultation (CICERO) pathfinder mission (Franklin et al. 2018). In this appendix, a brief summary is provided. Figure A1 shows a close-up of the resultant spatial sampling pattern when eight constellation satellites are separated by $2 \mathrm{~min}$, in a $45^{\circ}$ orbit inclination. In this depiction, each "cluster" of the eight satellites is assigned a unique color. Once the occultation from the first satellite (leading satellite, denoted as RO-1) in the constellation initiates (i.e., RO-1 locks on to the GNSS signal), about 2-3 min elapse until the occultation terminates, depending upon the orientation of the occultation ray path relative to the receiving antenna. Several minutes later, the occultation between the second satellite (RO-2) and the GNSS transmitting satellite starts. If RO-1 and RO-2 track the same GNSS transmitting satellite, the $\mathrm{RO}$ ray paths laid out by RO-1 and RO-2 are oriented approximately "parallel" to each other (Earth has rotated underneath the satellites in the intervening time). This sequence of occultation opportunities then arises for the remaining satellites in the constellation, RO-3, RO-4, .., RO-8. The sampling pattern is such that the eight RO ray paths are closely spaced but do not intersect, each sampling a unique air mass.

The ideal case would be when an occultation occurs between all eight constellation satellites and the same GNSS transmitting satellite. Once the occultation from RO-1 begins, a 16-min time window (maximum) opens up whereby this condition occurs. This is the rationale for the $8 \times 2$-min separation shown (if a ninth satellite is added, by the time that RO-9 flies near RO8 , the GNSS transmitting satellite is out of view). Such a configuration would be able to capture a time sequence of closely spaced RO profiles, whenever the constellation orbited across precipitating weather systems. Note from Fig. A1 the wide variability on the separation of the adjacent tangent point (TP), and the spacing between individual ray paths. The distribution of these orientations in relation to sampling of actual precipitation conditions is discussed in Turk et al. (2019).

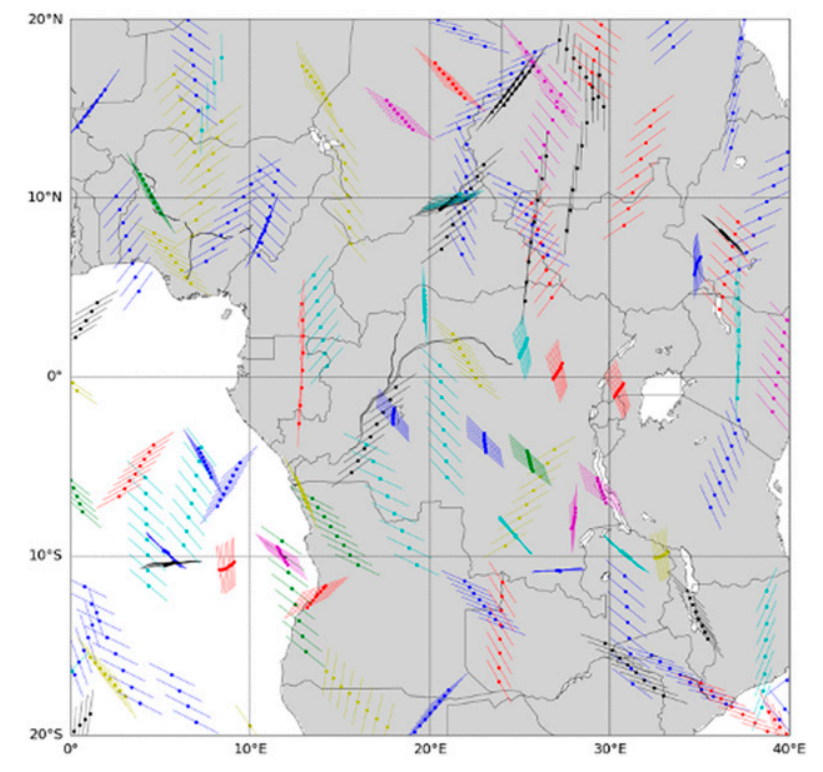

FIG. A1. Close-up to the $20^{\circ} \mathrm{S}-20^{\circ} \mathrm{N}, 0^{\circ}-40^{\circ} \mathrm{E}$ area, showing the RO tangent point locations (points) and the associated $200-\mathrm{km}$ ray-path segments (lines) for the case when the eight satellites are separated by $2 \mathrm{~min}$, orbiting in $45^{\circ}$ asynchronous orbit. Each "cluster" of the eight satellites is assigned a unique color. These simulated locations cover a 1-day period and RO opportunities with the GPS, GLONASS, Galileo, and BeiDou GNSS telemetries.

The ray path lines represent the path upon which the corresponding air mass thermodynamics would be sampled from each constellation satellite. Heavy precipitation is often associated with horizontal moisture gradients. For example, if the successive RO ray paths were oriented parallel to and spread across a frontal boundary (some RO capture the dry side; other RO the moist side), the surrounding moisture structure will be interpreted differently than if the RO were aligned in a more perpendicular orientation relative to the front (similar moisture captured across all RO). If available simultaneously, wideswath passive MW observations have the potential to augment and improve the interpretation of these RO, providing the precipitation context.

\section{APPENDIX B}

\section{Assumptions on Ice Particle Shape}

To assess the validity of the use of simple spheroid ice shapes for this investigation, the scattering properties of these approximate particles are compared with the results of more realistic particle shape models (Padullés et al. 2021). For these computations, forward scattering geometry and an L-band (1.4-GHz) frequency are used. In addition, the particles have been oriented horizontally with respect to the incident wave, therefore maximizing the value of the specific propagation differential phase shift $\left(K_{\mathrm{dp}}\right)$. During an RO rising or setting event, the Earth incidence angle anywhere along the ray path never exceeds $3^{\circ}$. The quantity of interest for this study is the 


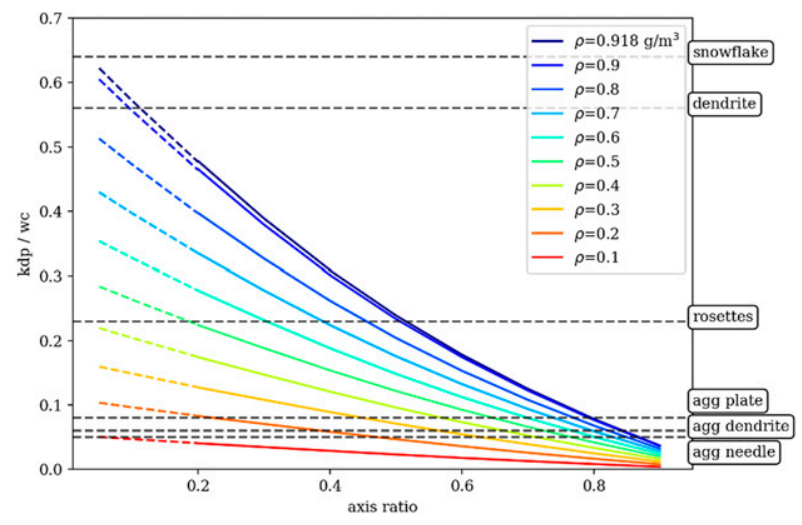

FIG. B1. Result for the scattering properties of different particle shapes and approximations. The $K_{\mathrm{dp}} / M$ ratio as a function of axis ratio ( $x$ axis) and density (colored lines) are shown for different spheroid approximations. The dashed portion of the colored lines is obtained through extrapolation. The dashed horizontal black lines (constant $K_{\mathrm{dp}} / M$ ) are the results obtained using realistic particle shapes (labeled accordingly) with the ADDA software.

$2 \times 2$ scattering amplitude matrix [S]. Due to the orientation of the particles, only the information in the copolar components of [S] $\left(S_{\mathrm{hh}}\right.$ and $\left.S_{\mathrm{vv}}\right)$ is retained (Bringi and Chandrasekar 2001). The particle shapes that are considered are 1) single pristine ice crystals, 2) aggregates formed by multiple single crystals of different sizes (Leinonen and Moisseev 2015), and 3) homogeneous spheroids with different effective densities and axis ratios (defined as the ratio of the minor $a$ to major axis $b$ ). Dielectric properties follow the Maxwell Garnett mixing formulations (Johnson et al. 2012).

The results for the (approximately linear) relationships between the mass and the specific differential phase shift for the different particles are shown in Fig. B1. The $K_{\mathrm{dp}}$ and water content $M$ are obtained by weighting the scattering properties (and mass) for the individual particles of different sizes by an ensemble of plausible particle size distributions. The results for the spheroids are shown as a function of the different particle axis ratios ( $x$ axis) and effective densities (different colors; see legend). These are compared with the ratio of $K_{\mathrm{dp}} / M$ obtained for the realistic shape particles computed with ADDA (Yurkin and Hoekstra 2011), indicated by the black horizontal dashed lines and labeled accordingly.

The results show how the results for approximate spheroids agree well with what one intuitively would expect. That is, lowdensity spheroids with a relatively wide range of axis ratio agree with the results using aggregates, while high-density (approaching pure ice) and low axis ratio spheroids agree better with single pristine ice crystals, which are in fact very thin. Note that the dashed portion of colored lines is obtained by extrapolation, since $\mathrm{T}$ matrix has convergence problems with very low axis ratios. The long wavelength (L band) also favors the agreement found using simple approximations, and the path-integrated nature of the polarimetric RO measurement make more complex computations unnecessary for the purposes of this study.

\section{REFERENCES}

Ahmed, F., and J. D. Neelin, 2018: Reverse engineering the tropical precipitation-buoyancy relationship. J. Atmos. Sci., 75, 1587-1608, https://doi.org/10.1175/JAS-D-17-0333.1.

Ao, C. O., D. E. Waliser, S. K. Chan, J.-L. Li, B. Tian, F. Xie, and A. J. Mannucci, 2012: Planetary boundary layer heights from GPS radio occultation refractivity and humidity profiles. J. Geophys. Res., 117, 16117, https://doi.org/10.1029/2012JD017598.

Aonashi, K., and H. Eito, 2011: Displaced ensemble variational assimilation method to incorporate microwave imager brightness temperatures into a cloud-resolving model. J. Meteor. Soc. Japan, 89, 175-194, https://doi.org/10.2151/jmsj.2011-301.

Battaglia, A., and Coauthors, 2020: Spaceborne cloud and precipitation radars: Status, challenges, and ways forward. Rev. Geophys. 58, e2019RG000686, https://doi.org/10.1029/2019RG000686.

Beard, K. V., and C. Chuang, 1987: A new model for the equilibrium shape of raindrops. J. Atmos. Sci., 44, 1509-1524, https://doi.org/ 10.1175/1520-0469(1987)044<1509:ANMFTE >2.0.CO;2.

Blackwell, W. J., and Coauthors, 2018: An overview of the TROPICS NASA Earth Venture mission. Quart. J. Roy. Meteor. Soc., 144 (Suppl.), 16-26, https://doi.org/10.1002/ qj.3290.

Bretherton, C. S., M. E. Peters, and L. E. Back, 2004: Relationships between water vapor path and precipitation over the tropical oceans. J. Climate, 17, 1517-1528, https://doi.org/10.1175/15200442(2004)017<1517:RBWVPA > 2.0.CO;2.

Bringi, V., and V. Chandrasekar, 2001: Polarimetric Doppler Weather Radar: Principles and Applications. Cambridge University Press, $636 \mathrm{pp}$.

Cardellach, E., and Coauthors, 2014: Sensitivity of the PAZ LEO polarimetric GNSS radio occultation experiment to precipitation events. IEEE Trans. Geosci. Remote Sens., 53, 190-206, https://doi.org/10.1109/TGRS.2014.2320309.

— , R. Padullés, S. Tomás, F. J. Turk, C. O. Ao, and M. de la Torre-Juárez, 2018: Probability of intense precipitation from polarimetric GNSS radio occultation observations. Quart. J. Roy. Meteor. Soc., 144 (Suppl.), 206-220, https://doi.org/ 10.1002/qj.3161.

—, and Coauthors, 2019: Sensing heavy precipitation with GNSS polarimetric radio occultations. Geophys. Res. Lett., 46, 1024-1031, https://doi.org/10.1029/2018GL080412.

de la Torre-Juárez, M., R. Padullés, F. J. Turk, and E. Cardellach, 2018: Signatures of heavy precipitation on the thermodynamics of clouds seen from satellite: Changes observed in temperature lapse rates and missed by weather analyses. J. Geophys. Res. Atmos., 123, 13 033-13 045, https://doi.org/ 10.1029/2017JD028170.

Fiolleau, T., and R. Roca, 2013: An algorithm for the detection and tracking of tropical mesoscale convective systems using infrared images from geostationary satellite. IEEE Trans. Geosci. Remote Sens., 51, 4302-4315, https://doi.org/10.1109/ TGRS.2012.2227762.

Foelsche, U., S. Syndergaard, J. Fritzer, and G. Kirchengast, 2011: Errors in GNSS radio occultation data: Relevance of the measurement geometry and obliquity of profiles. Atmos. Meas. Tech., 4, 189-199, https://doi.org/10.5194/amt-4-1892011.

Franklin, G., and Coauthors, 2018: A GNSS receiver for smallsats enabling precision POD, radio occultations, and reflections. Proc. SPIE, 10769, 1076905, https://doi.org/10.1117/ 12.2323830 .

Galligani, V. S., C. Prigent, E. Defer, C. Jimenez, and P. Eriksson, 2013: The impact of the melting layer on the passive micro- 
wave cloud scattering signal observed from satellites: A study using TRMM microwave passive and active measurements. J. Geophys. Res. Atmos., 118, 5667-5678, https://doi.org/ 10.1002/jgrd.50431.

Geerts, B., and Coauthors, 2018: Recommendations for in-situ and remote sensing capabilities in atmospheric convection and turbulence. Bull. Amer. Meteor. Soc., 99, 2463-2470, https:// doi.org/10.1175/BAMS-D-17-0310.1.

Gong, J., and Coauthors, 2020: Linkage among ice crystal microphysics, mesoscale dynamics, and cloud and precipitation structures revealed by collocated microwave radiometer and multifrequency radar observations. Atmos. Chem. Phys., 20, 12 633-12 653, https://doi.org/10.5194/acp-20-12633-2020.

Grecu, M., W. S. Olson, S. J. Munchak, S. E. Ringerud, L. Liao, Z. S. Haddad, B. L. Kelley, and S. F. Mclaughlin, 2016: The GPM combined algorithm. J. Atmos. Oceanic Technol., 33, 2225-2245, https://doi.org/10.1175/JTECH-D-16-0019.1.

Haddad, Z. S., D. A. Short, S. L. Durden, E. Im, S. Hensley, M. B. Grable, and R. A. Black, 1997: A new parametrization of the rain drop size distribution. IEEE Trans. Geosci. Remote Sens., 35, 532-539, https://doi.org/10.1109/36.581961.

—, R. C. Sawaya, S. Kacimi, O. O. Sy, F. J. Turk, and J. Steward, 2017: Interpreting millimeter-wave radiances over tropical convective clouds. J. Geophys. Res. Atmos., 122, 1650-1664, https://doi.org/10.1002/2016JD025923.

Ho, S.-P., and Coauthors, 2020: Initial assessment of the COSMIC-2/FORMOSAT-7 neutral atmosphere data quality in NESDIS/STAR using in-situ and satellite data. Remote Sens., 12, 4099, https://doi.org/10.3390/rs12244099.

Iacovazzi, R., L. Lin, N. Sun, and Q. Liu, 2020: NOAA operational microwave sounding radiometer data quality monitoring and anomaly assessment using COSMIC GNSS radio occultation soundings. Remote Sens., 12, 828, https://doi.org/10.3390/ rs12050828.

Iguchi, T., N. Kawamoto, and R. Oki, 2018: Detection of intense ice precipitation with GPM/DPR. J. Atmos. Oceanic Technol., 35, 491-502, https://doi.org/10.1175/JTECH-D-17-0120.1.

Isoz, O., S. A. Buehler, and P. Eriksson, 2015: Intercalibration of microwave temperature sounders using radio occultation measurements. J. Geophys. Res. Atmos., 120, 3758-3773, https://doi.org/10.1002/2014JD022699.

Johnson, B. T., G. W. Petty, and G. Skofronick-Jackson, 2012: Microwave properties of ice-phase hydrometeors for radar and radiometers: Sensitivity to model assumptions. J. Appl. Meteor. Climatol., 51, 2152-2171, https://doi.org/10.1175/ JAMC-D-11-0138.1.

Kidd, C., J. Tan, P.-E. Kirstetter, and W. A. Petersen, 2018: Validation of the version 05 level 2 precipitation products from the GPM Core Observatory and constellation satellite sensors. Quart. J. Roy. Meteor. Soc., 144 (Suppl.), 313-328, https://doi.org/10.1002/qj.3175.

Kummerow, C. D., D. L. Randel, M. Kulie, N.-Y. Wang, R. R. Ferraro, S. J. Munchak, and V. Petkovic, 2015: The evolution of the Goddard profiling algorithm to a fully parametric scheme. J. Atmos. Oceanic Technol., 32, 2265-2280, https:// doi.org/10.1175/JTECH-D-15-0039.1.

Kuo, Y.-H., K. A. Schiro, and J. D. Neelin, 2018: Convective transition statistics over tropical oceans for climate model diagnostics: Observational baseline. J. Atmos. Sci., 75, 15531570, https://doi.org/10.1175/JAS-D-17-0287.1.

Kursinski, E. R., G. A. Hajj, J. T. Schofield, R. P. Linfield, and K. R. Hardy, 1997: Observing Earth's atmosphere with radio occultation measurements using the global positioning system.
J. Geophys. Res., 102, 23 429-23 465, https://doi.org/10.1029/ 97JD01569.

Lasota, E., W. Rohm, C.-Y. Liu, and P. Hordyniec, 2018: Cloud detection from radio occultation measurements in tropical cyclones. Atmosphere, 9, 418, https://doi.org/ 10.3390/atmos9110418.

Leinonen, J., and D. Moisseev, 2015: What do triple-frequency radar signatures reveal about aggregate snowflakes? J. Geophys. Res. Atmos., 120, 229-239, https://doi.org/10.1002/2014JD022072.

Liu, S., C. Grassotti, Q. Liu, Y.-K. Lee, R. Honeyager, Y. Zhou, and M. Fang, 2020: The NOAA Microwave Integrated Retrieval System (MiRS): Validation of precipitation from multiple polar-orbiting satellites. IEEE J. Sel. Top. Appl. Earth Obs. Remote Sens., 13, 3019-3031, https://doi.org/ 10.1109/JSTARS.2020.3000348.

Mannucci, A. J., C. O. Ao, X. Pi, and B. A. Iijima, 2011: The impact of large-scale ionospheric structure on radio occultation retrievals. Atmos. Meas. Tech., 4, 2837-2850, https://doi.org/ 10.5194/amt-4-2837-2011.

Mascio, J., S. S. Leroy, R. P. d'Entremont, T. Connor, and E. R. Kursinski, 2021: Using radio occultation to detect clouds in the middle and lower troposphere. Eighth Int. Radio Occultation Working Group, Virtual, UCAR, https://cpaess.ucar.edu/sites/ default/files/meetings/2020/presentations/mascio-presentation.pdf.

Matrosov, S. Y., A. J. Heymsfield, and Z. Wang, 2005: Dual-frequency radar ratio of nonspherical atmospheric hydrometeors. Geophys. Res. Lett., 32, L13816, https://doi.org/10.1029/2005GL023210.

Mischenko, M. I., L. D. Travis, and D. W. Mackowski, 1996: T-matrix computations of light scattering by nonspherical particles: A review. J. Quant. Spectrosc. Radiat. Transfer, 55, 535-575, https://doi.org/10.1016/0022-4073(96)00002-7.

Murphy, M. J., J. S. Haase, R. Padullés, S. H. Chen, and M. A. Morris, 2019: The potential for discriminating microphysical processes in numerical weather forecasts using airborne polarimetric radio occultations. Remote Sens., 11, 2268, https:// doi.org/10.3390/rs11192268.

Padullés, R., C. O. Ao, F. J. Turk, M. de la Torre Juárez, B. Iijima, K. N. Wang, and E. Cardellach, 2020: Calibration and validation of the polarimetric Radio Occultation and Heavy Precipitation experiment aboard the PAZ satellite. Atmos. Meas. Tech., 13, 1299-1313, https://doi.org/10.5194/amt-13-1299-2020.

—, E. Cardellach, F. J. Turk, C. O. Ao, M. de la Torre Juarez, J. Gong, and D. Wu, 2021: Sensing horizontal oriented frozen particles with polarimetric radio occultations aboard PAZ: Validation using GMI coincident observations and CloudSat a-priori information. IEEE Trans. Geosci. Remote Sens., https://doi.org/10.1109/TGRS.2021.3065119, in press.

Romps, D. M., 2014: An analytical model for tropical relative humidity. J. Climate, 27, 7432-7449, https://doi.org/10.1175/JCLI-D-14-00255.1.

Ruston, B., and S. Healy, 2021: Forecast impact of FORMOSAT-7/ COSMIC-2 GNSS radio occultation measurements. Atmos. Sci. Lett., 22, e1019, https://doi.org/10.1002/asl.1019.

Schiro, K. A., and J. D. Neelin, 2019: Deep convective organization, moisture vertical structure, and convective transition using deep-inflow mixing. J. Atmos. Sci., 76, 965-987, https:// doi.org/10.1175/JAS-D-18-0122.1.

—, S. C. Sullivan, Y.-H. Kuo, H. Su, P. Gentine, G. S. Elsaesser, J. H. Jiang, and J. D. Neelin, 2020: Environmental controls on tropical mesoscale convective system precipitation intensity. J. Atmos. Sci., 77, 4233-4249, https://doi.org/10.1175/JAS-D-20-0111.1.

Sherwood, S. C., S. Bony, and J. L. Dufresne, 2014: Spread in model climate sensitivity traced to atmospheric convective mixing. Nature, 505, 37-42, https://doi.org/10.1038/nature12829. 
Stephens, G., and Coauthors, 2020a: The emerging technological revolution in Earth observations. Bull. Amer. Meteor. Soc., 101, E274-E285, https://doi.org/10.1175/BAMS-D-19-0146.1.

_- and Coauthors, 2020b: A distributed small satellite approach for measuring convective transports in the Earth's atmosphere. IEEE Trans. Geosci. Remote Sens., 58, 4-13, https:// doi.org/10.1109/TGRS.2019.2918090.

Sy, O. O., and Coauthors, 2021: Scientific products from the first radar in a CubeSat (RainCube): Deconvolution, cross-validation, and retrievals. IEEE Trans. Geosci. Remote Sens., https://doi.org/ 10.1109/TGRS.2021.3073990, in press.

Tapiador, F. J., R. Roca, A. Del Genio, B. Dewitt, W. A. Petersen, and F. Zhang, 2019: Is precipitation a good metric for model performance? Bull. Amer. Meteor. Soc., 100, 223-233, https:// doi.org/10.1175/BAMS-D-17-0218.1.

Turk, F. J., Z. S. Haddad, P.-E. Kirstetter, Y. You, and S. E. Ringerud, 2018: An observationally based method for stratifying a priori passive microwave observations in a Bayesian-based precipitation retrieval framework. Quart. J. Roy. Meteor. Soc., 144 (Suppl.), 145-164, https://doi.org/10.1002/qj.3203.

— constellation of atmospheric polarimetric radio occultation measurements. Remote Sens., 11, 2399, https://doi.org/10.3390/ rs11202399.

— , and Coauthors, 2021: Applications of a CloudSat-TRMM and CloudSat-GPM satellite coincidence dataset. Remote Sens., 13, 2264, https://doi.org/10.3390/rs13122264.

Utsumi, N., F. J. Turk, Z. S. Haddad, P.-E. Kirstetter, and H. Kim, 2020: Evaluation of precipitation vertical profiles estimated by GPM-era satellite-based passive microwave retrievals.
J. Hydrometeor., 22, 95-112, https://doi.org/10.1175/JHM-D20-0160.1.

Waliser, D. E., and Coauthors, 2009: Cloud ice: A climate model challenge with signs and expectations of progress. J. Geophys. Res., 114, D00A21, https://doi.org/10.1029/2008JD010015.

Wang, D., C. Prigent, F. Aires, and C. Jimenez, 2017: A statistical retrieval of cloud parameters for the Millimeter Wave Ice Cloud Imager onboard MetOp-SG. IEEE Access, 5, 40574076, https://doi.org/10.1109/ACCESS.2016.2625742.

Wang, K.-N., C. O. Ao, R. Padullés, F. J. Turk, M. de la TorreJuárez, and E. Cardellach, 2021: The effects of heavy precipitation on polarimetric radio occultation (PRO) bending angle observations. J. Atmos. Oceanic Technol., https://doi.org/ 10.1175/JTECH-D-21-0032.1, in press.

Wu, D. L., and Coauthors, 2009: Comparisons of global cloud ice from MLS, CloudSat, and correlative data sets. J. Geophys. Res., 114, D00A24, https://doi.org/10.1029/2008JD009946.

You, Y., V. Petkovic, J. Tan, R. Kroodsma, W. Berg, C. Kidd, and C. Peters-Lidard, 2020: Evaluation of V05 precipitation estimates from GPM constellation radiometers using KuPR as the reference. J. Hydrometeor., 21, 705-728, https://doi.org/ 10.1175/JHM-D-19-0144.1.

Yurkin, M. A., and A. G. Hoekstra, 2011: The discrete-dipoleapproximation code ADDA: Capabilities and known limitations. J. Quant. Spectrosc. Radiat. Transfer, 112, 2234-2247, https://doi.org/10.1016/j.jqsrt.2011.01.031.

Zipser, E. J., D. J. Cecil, C. Liu, S. W. Nesbitt, and D. P. Yorty, 2006: Where are the most intense thunderstorms on Earth? Bull. Amer. Meteor. Soc., 87, 1057-1072, https://doi.org/ 10.1175/BAMS-87-8-1057. 